\title{
تاريخ التواصل الاجتماعي خلال الجوائح التاريخية - مقارنة بين جائحة الإنفلونزا الإسبانية وجائحة كورونا 9 أب ب- دراسة بينيّة
}

\author{
د. حسن بن عبد الله الأسمري \\ استاذ مساعد - كلية العلوم والاد/ب برابغ \\ قسم مهارات الاتصال
}

مستخص. هدفت هذه الدراسة إلى بيان طبيعة التواصل الاجتماعي أثثاء الجوائح الكبري، ولتحقيق هذا الهدف، اعتمدت هذه الدراسة على المنهج الوصفي وذلك لتوصيف الإطار العام للظاهرة المتعلقة بالجوائح الكبرى عامة، وبجائحتي الإنفلونزا • ب 9 (، وكوفيد 9 (1 على وجه الخصوص، كما تم استخدام المنهج المقارن، وذلك لتوضيح الفروق

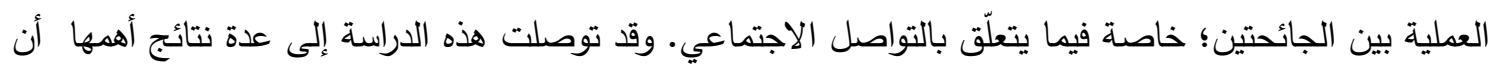
الجوائح ظاهرة إنسانية تتكرر في حياة البشر ، وللأسف فإن سبب حدوثها الرئيسي مرتبط بسلوك الإنسان؛ خاصة فيما

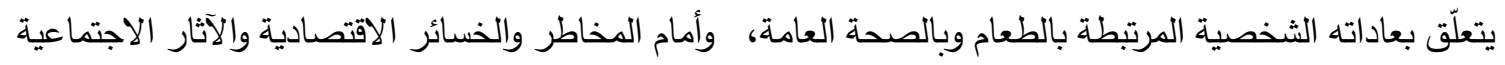
التي تسبيها هذه الجوائح، فإن دور وسائل التواصل الاجتماعي والفضائيات يغدو أكثر مركزية وأهمية في مواجهة هذه الآثار ، خاصة مع إمكانية مباشرة العمل والتجارة من المنزل. لوندان. الكلمات المفتاحية : التواصل الاجتماعي ، الجوائح ، الإنفلونزا ، كورونا.

وتأثيره على وجود وانتشار الجوائح من ناحية، وتأثير المقدمة

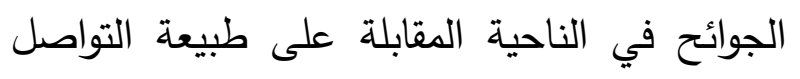

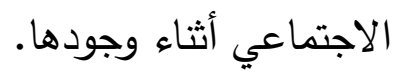
ولا شك أن طبيعة الموضوع وطبيعة تتاوله اقتضت التاء وجودها. العودة إلى طائفة واسعة من المراجع، تدور في ثلاثة
يتناول هذا البحث تاريخ التواصل الاجتماعي خلال الجوائح التاريخية، بالمقارنة بين نموذجي الجائحتين:

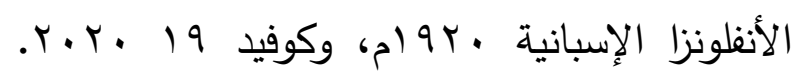
وهذا التناول يهدف إلى بيان طبيعة هذا التواصل 
وجعله المصدر المعتد في عرض هذه المعلومة أو تلك.

وإذ اعتمد الباحث في الأكثر، على نسخ الكترونية

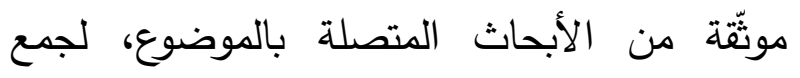
المعلومات وتصنيفها وتوثيقها في العرض، فقد اجتهدت في عدم الاكتفاء بالنقل عن تلك المراجع، وحاولت تحليل المعلومات، من خلال اختيار أقربها بموضوع البحث، وعرض المعلومة المختارة في سياق تحليل العلاقة بين التواصل الاجتماعي والجوائح

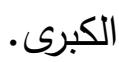

ولذلك، أهملت المعلومات التقصيلية التي تتصل مثالا ـ بالأعراض المرضية، وبالتشخيص السريري لأمراض الجوائح، وركّزت عرضي على ما يتصل منها بطبيعة التواصل الاجتماعي، إذ إن هذا التواصل وطبيعته أثناء الجوائح الكبرى هو الموضوع المستهدف للبحث.

ولتحقيق هذا الهدف، فقد قسمت بحثي إلى إطار نظري، ومبحثين، وخاتمة. في الإطار النظري أتتاول فيه موضوع البحث وأهدافه وأسئلته، وتاريخ البحث الإطين فيه من خلال الدراسات السابقة في الموضوع، ثم المنهج الذي أتبعه في هذا التناول. أما المبحث الأول ـ الجوائح وتاريخها: فأتناول فيه ظاهرة الجوائح من الناحية التاريخية، مبرزا في ذلك نموذجي البحث: الإنفلونزا الإسبانية وكوفيد ـ 9 (6) وأثر الجوائح على المجتمع؛ خاصة فيما يتعلّق بالاقتصاد وبعلاقات التواصل الاجتماعي. والمبحث
مجالات كبرى: التواصل الاجتماعي، والجوائح الكبرى وتأثيراتها في حياة الإنسان، قديما وحديثا، وطبيعة الإجراءات المتخذة لمواجهتها ومعالجة الأزمة، ثم التأثير الاجتماعي والاقتصادي، لمثل هذه الجوائح.

وهذا التناول الوسع للموضوع في مجالات متعددة، مثّل عقبة رئيسية من عقبات هذا البحث ومشاقّه؛ إذ إن قراءة هذه الدراسات تقتضي الجمع والتوفيق بين معلوماتها، وانتقاء ما يناسب موضوع البحث، ثم تحليله. وهذا أمر فيه صعوبة، لاختلاف المجالات التي تعالجها هذه الأبحاث، ولاختلاف الأهداف، وهذا، وطرق التتاول والعرض فيها. ويتصل بهذا الموضوع من صعوبات، كون كثير من المعلومات الرئيسية المتعلّقة بالجوائح تتكرر من مصدر إلى آخر ، وأكثرها معروض في موقع وكيبيديا الذي ينقل عنه الباحثون، ما يجعل من المصدر غير أصليّ في عرض موضوعد، إضافة إلى صعوبة الاعتماد على (وكيبيديا) في هذا المجال. ويمكن أن نضيف أيضا، أن كثيرا من المراجع الأصلية في هذه المجالات المختلفة غير متوفرة على نحو مباشر ، وهو الأمر الذي زاد من صعوبة البحث، خاصة حين اعتمدت على نسخ الكترونية موثّقة منها. وقد حاول الباحث التغلّب على هذه المشاقّ المركّبة بمحاولة الجمع بين المصادر والدراسات المختلفة في الموضوع الواحد، واختيار أكثرها أصالة في التوثيق، 
r ـ أثر التواصل الاجتماعي على انتشار الجوائح الكبرى، وتحويل الأمراض المعدية إلى أوبئة

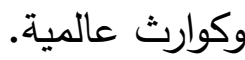

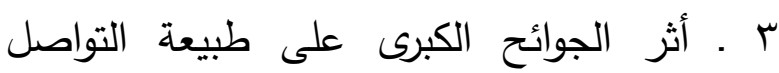

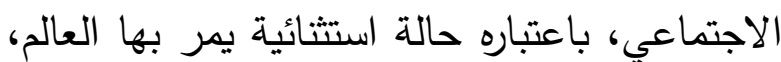
في لحظة تاريخية من حياته. ـ ـ بيان الكيفية التي يجب بها أن نتعامل مع الجوائح الكبرى، من خلال توظيف تكنولوجيا التواصل في مواجهة الأزمة ومعالجة آثارها الكارثية. 0. بيان الفرق بين جائحتي الإنفلونزا • ب 9 ام وكوفيد 19 الاجتماعي.

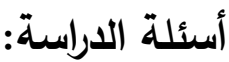
وفي ضوء الأهداف السابقة، يمكن تحديد أسئلة الدراسة على النحو التالي: - الي: السؤال الرئيسي: ما هي طبيعة التواصل الاجتماعي أثناء الجوائح الكبرى؟ التئ الأسئلة الفرعية: ا. كيف يؤثّر التواصل الاجتماعي على انتشار

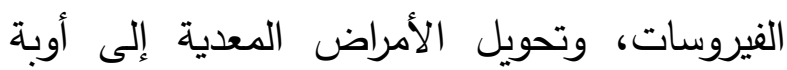
وجوائح عالمية؟ r. ما هي تأثيرات الجوائح الكبرى على طبيعة التواصل الاجتماعي في زمن وجودها وانتشارها؟

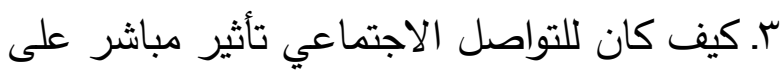

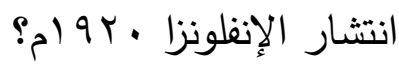

الثاني ـ التواصل الاجتماعي في إطار الجوائح، حيث أتتاول مفهوم التواصل الاجتماعي وطبيعته، وحدود المسؤولية الاجتماعية وعلاقتها بمواجهة الجائحة ومعالجة آثارها. أما الخاتمة، فقد خصصتها لاستخلاص العلاقات الأساسية بين التواصل الاجتماعي وانتشار الجائحة ثم مواجهتها ومعالجة آثارها، ومن ثم استخلاص أبرز النتائج المترتبة على ذلك. وفي الأخير وضعت قائهة بالمراجع التي اعتمدت عليها في هذا البحث. ويجدر هنا أن أشير إلى أنني قسمت كل مبحث من المبحثين المذكورين في هذه الدراسة، إلى مجموعة من العناوين التي تستوفي موضوع البحث وأفكاره

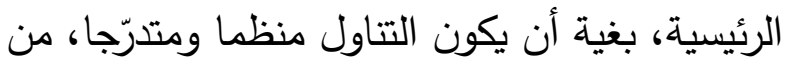
فكرة الجائحة كظاهرة إنسانية، إلى مفهوم التواصل لتهل الاجتماعي، كمفهوم وممارسة إنسانية تتصل بكل الظواهر الفاعلة في حياة الإنسان. وبعد، فإنني أرجو

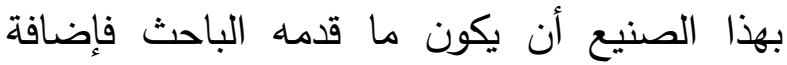

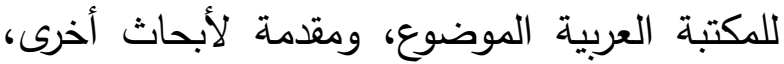
تستوفي النقاط التي لم يتطرق إليها البحث.

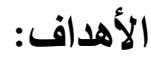
وفي ضوء ما حددته لموضوع البحث من أطر نظرية وعملية، فإن أهدافه تتحصر في : الهدف الرئيسي - بيان طبيعة التواصل الاجتماعي أثناء الجوائح الكبري.

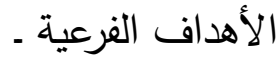
ا. طبيعة التواصل الاجتماعي. 
اهتمامه الخاص، وله أهدافه المستقلة. وبالتأمل، فإن الباحث يلاحظ أن كل دراسة من تلك الدراسات لم

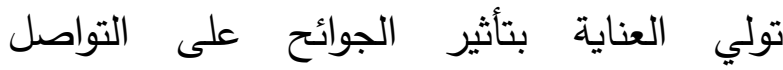
الاجتماعي، ولا بتأثير التواصل الاجتماعي على الجوائح. صحيح أن كثيرا منها أشار إلى هذه التأثيرات بحكم طبيعة التناول نفسه، لكن واحدة منها لم تخصّص موضوعها لدراسة التأثير المتبادل بين الظاهرتين: التواصل الاجتماعي، والجوائح. ومن هنا تبرز أهمية هذه الدراسة؛ إذ إنها تحاول أن تستوفي هذا الجانب المنقوص في تلك الدراسات، دون أن يعني هذا النقص عيبا فيها، وإنما أردت أنها فحسب لم تولي عنايتها لموضوعي في هذا البحث. وبالتالي، تظهر أهمية بحثي في نقطتين رئيسيّتين: الأولى - جدة التناول، من حيث كونه بحثا جديدا في موضوعه، وصعبا في تحقيق أهدافه. والثانية ـ ـبيعة الدراسة، باعتبارها دراسة بينيّة، تتجاوز التخصّص المباشر، سواء في التواصل الاجتماعي، أو في الجوائح كظاهرة إنسانية، تتجاوزه إلى الجمع بين المجالين، لعلها بذلك تُوفّق في إبراز نقاط غائبة عن طبيعة الموضوع، بما يمكّن الباحث / الباحثين في المستقبل من البناء عليها في تناول نقاط أخرى، وإضاءة مناطق جديدة في الموضوع. ه. حدود الدراسة:

أما الحدود الموضوعية لهذا البحث، وفي ضوء أهدافه وأسئلته، فإنها تتحدّد في:
ع. كيف كان للتواصل الاجتماعي تأثير مباشر على

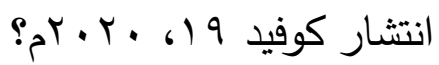
0. ما هو الفرق بين طبيعة التواصل الاجتماعي أثناء

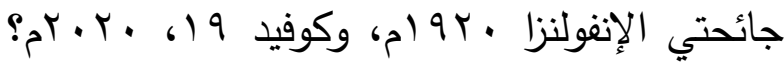
7. كيف يجب أن نتعامل مع الجوائح الكبرى من خلال توظيف تكنولوجيا التواصل ؟ أهمية الارراسة: إذا كان موضوع البحث يتناول طبيعة التواصل الاجتماعي أثثاء الجوائح الكبرى، بالتطبيق على

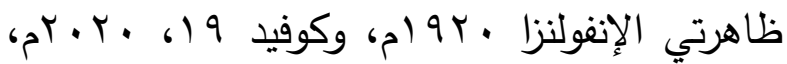
فإن الدراسات المتعلقة بهذا الموضوع تدور حول: ا. التواصل الاجتماعي وطبيعته، أثناء الجوائح خاصة، وفي غير وجودها بشكل عام. r. الجوائح الكبرى وطبيعتها وتأثيرها في التاريخ الإنساني. r. جائحتي الإنفلونزا الإسبانية . ب 9 (م، وكوفيد 19

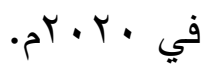
والحقيقة أن المكتبة العربية تمتلئ بعشرات الدراسات التي تتناول هذه الموضوعات كإطار عام لظاهرة الجوائح، لكنها لا تسير في الإطار الموضوعي نفسه، فبعضها يهتم بتوصيف ظاهرة التواصل الاجتماعي، وبعضها يهتم بتوصيف الجوائح وتأثيراتها، والبعض الأخير يهتم بتوصيف ظاهرتي الإنفلونزا • ب أم، وكوفيد 9 1 في •r •rم. وهذا الاختلاف بين الدراسات التي دارت حول هذه الموضوعات الثلاثة طبيعيّ؛ إذ إن كل واحد منها لله 
المعلومات والنتائج التي تتصل اتصالا مباشرا بموضوع هذا البحث. أولا - دراسات تتعلّق بالتواصل الاجتماعي: 1. دراسة إيمان صابر صادق: العوامل المؤثرة على لى

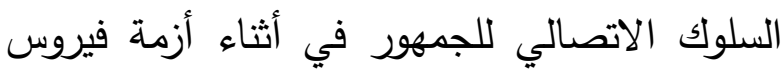

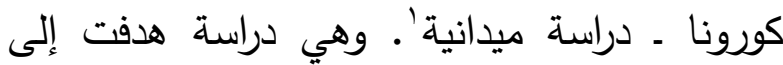
الكثف عن العوامل المؤثرة على السلوك الاتصالي وتفسير اتجاهات الجمهور تجاه المعالجة. وقد اعتمدت الدراسة على منهج المسج الإعلامي، وأداة الاستبانة والمقابلة، وخلصت في نتائجها إلى وجود صلة بين الثقة في مصادر المعلومات ومشاركتها، والالتزام بالإجراءات الاحترازية المنشورة عبر وسائل الإعلام، مع وجود تفاوت في درجة الالتزام حسب بلإب الاحترله الفئة العمرية ودرجة الوعي والثقافة. ז. دراسة فاطمة سعود عبدالعزيز السالم: مصداقية الإعلام الرسمي الكويتي أثناء الأزمات ـ ـ جائحة

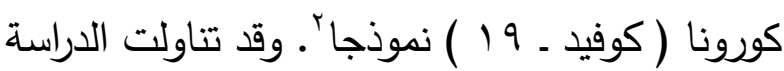
مصداقية الإعلام الرسمي الكويتي أثناء الأزمات، بالتطبيق على جائحة كوفيد ـ 9 ا كنموذج للأزمات والجوائح. وقد لاحظت الدراسة ارتفاع استخدام وسائل التواصل الاجتماعي مع غياب التقييم الممنهج لوسائل الإعلام خاصة. وقد اعتمدت الدراسة على استبانة تحدد عوامل المصداقية وارتباطها باستخدام وسائل الإعلام. وقد توصلت الدراسة إلى نتائج من أهمها
الحد الموضوعي : طبيعة وأثر التواصل الاجتماعي على وجود وانتشار الجوائح الكبرى. الحد الزماني: الجوائح الكبرى في حياة الإنسان، من فجر التاريخ المعروف للجوائح إلى اللحظة الحاضرة، حيث كوفيد 9 أي •r.r. الحد المكاني: الحدود المكانية لانتشار الجوائح في العالم عامة، وتأثيرها في المكان المحدود للدول

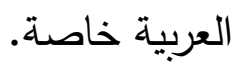

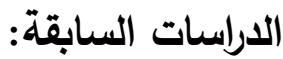
وفي ضوء ما ذكرته عن طبيعة الدراسات السابقة، فإنه يمكن عرض مجموعة منها؛ كمثال يبيّن حدودها وأطرها الرئيسية. وبطبيعة الحال، فإنني سأكتفي بعرض نماذج منها، تتصل مباشرة بموضوع هذا لبطها

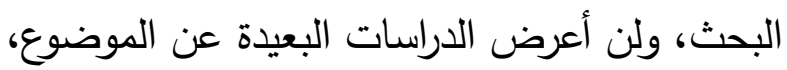
لكثرة هذه الدراسات ـ مباشرة وغير مباشرة ـ ولصعوبة

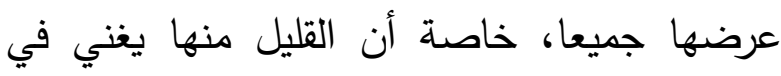
مسالة تحقيق الهدف من عرض الدراسات السابقة، فالهدف هو بيان طبيعة التناول السابق للموضوع، إضافة إلى عرض جانب من المصادر الرئيسية في

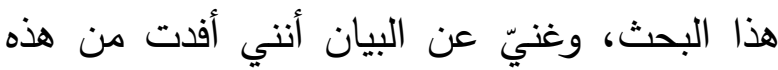
الدراسات، سواء من ناحية افكارها، او معلوماتها

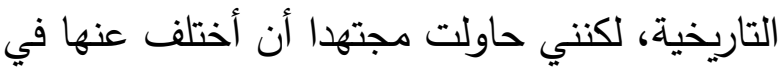
طريقة العرض، وفي طريقة التحليل واستخلاص

' إيمان صادق صابر : العو امل المؤثرة على السلوك الاتصالي للجمهور

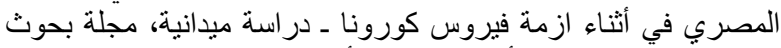

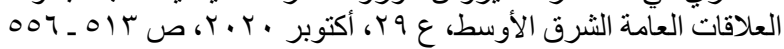


المغرب خلال القرنين الخامس عشر والسادس عشر، في زمن الوطاسيين. والدراسة تاريخية، انتهات في

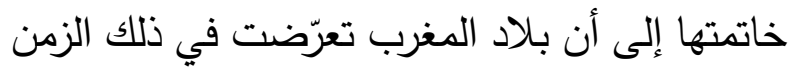
إلى نزيف بشري حقيقي، نتيجة الأوبئة والجوائح والكوارث المختلفة التي تعرضت لها، ولعل أسوأها هو انهيار القيم الاجتماعية، تأسيسا على انهيار النظامين

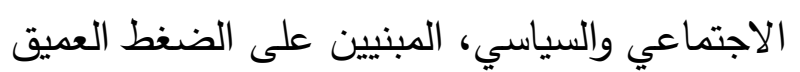
الذي خلّفته الكوارث الطبيعية والجوائح المرضية في الإيتي الطيني تلك الفترة. ه ـ كتاب شلدون واتس: الأوبئة والتاريخ ـ المرض والقوة الإمبريالية؛ وهو كتاب يتتاول تاريخ الأوبئة في العالم، وعلاقتها بالممارسات السلطوية ودورها في انتثار الأوبئة؛ خاصة في المناطق الفقيرة من العالم. والكتاب في إجماله يدور حول الممارسات الطبية ودورها في نقل المعرفة حول العالم، وأيضا دورها في دولي ترسيخ سيطرة الغرب على العالم، وذلك من خلال ستة فصول تتناول الجدري والحمى الصفراء والكوليرا

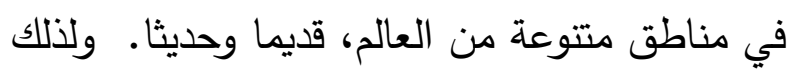

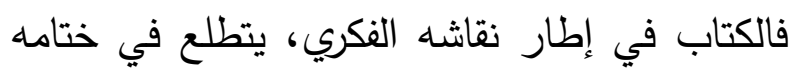
(الفصل السابع) إلى تأسيس علم جديد للأوبئة،

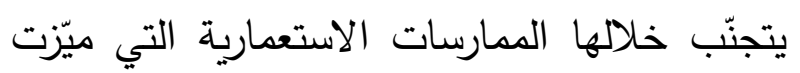

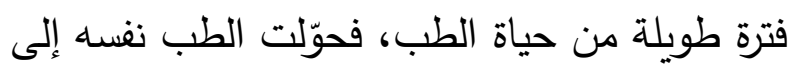

؛ ـ عبدالله استيتو: الجوائح و السلطة و الدين في المغرب زمن العن الوطاسيين

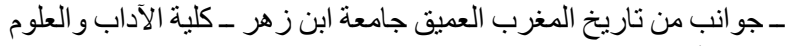

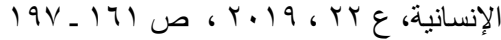

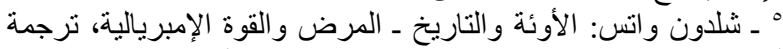

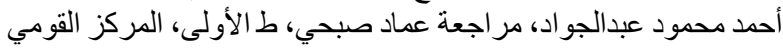

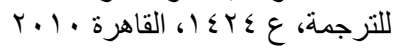

ازدياد الثقة في وسائل الإعلام أثناء الأزمة، مع زيادة

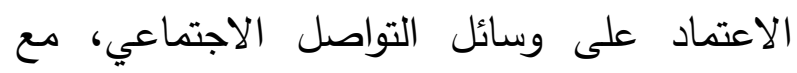
حصول الصحافة على أعلى معدل ثقة من بين وسائل الإعلام المختلفة. r. دراسة سارة سعيد عبد الجواد: اعتماد الجمهور

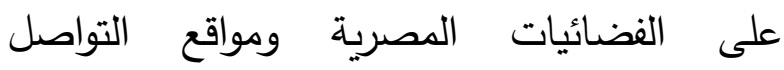
الاجتماعي كمصدر لتعزيز الوعي حول جائحة

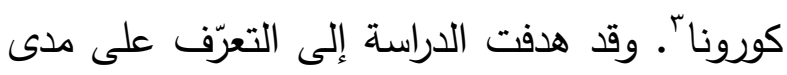
اعتماد الجمهور على الفضائيات ووسائل التواصل الاجتماعي كمصدر لتعزيز الوعي حول جائحة كورونا، وكذلك رصد المسؤولية الاجتماعية لهذه الوسائل واستخلاص رؤية مستقبلية لتعزيز الوعي بناء على مقترحات الجمهور نفسه. وقد خلصت الدراسة إلى ارتفاع نسبة اعتماد الجمهور على الفضائيات في مقابل وسائل التواصل الاجتماعي الأخرى في تعزيز الوعي بمواجهة الأزمة. ثانيا ـ دراسات تتعلّق بالجوائح الكبرى وطبيعتها وتأثيرها في التاريخ الإنساني: داني ع. دراسة عبدالله استيتو : الجوائح والسلطة والدين في لإسي المغرب زمن الوطاسيين - جوانب من تاريخ المغرب

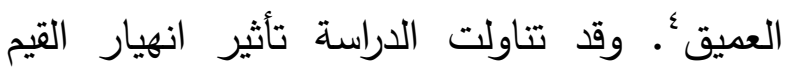
الخلقية والعقائدية في بلاد المغرب العربي على الحياة الاجتماعية، وذلك بسبب تأثير الجوائح التي مرت بها

r ـ سارة سعيد عبدالجواد: اعتماد الجمهور على الفضائيات المصرية

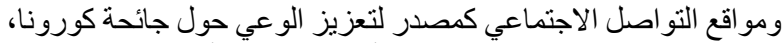

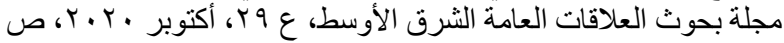


V . دراسة عائشة بشير التايب: الجائحة والمضامين

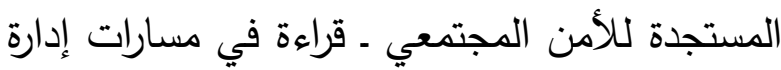

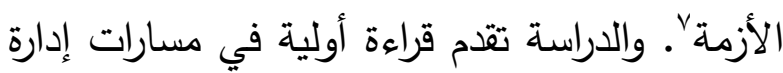
الأزمة، خاصة في البلدان العربية، وتأثير هذه الإدارة

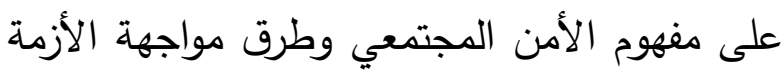
في إطارها. وقد اتبعت الدراسة منهجية وصفية تحليلية، وتوصلت إلى عدة نتائج، من أبرزها دور الفئات الاجتماعية المختلفة في مساعدة السلطات الرسمية على مواجهة الجائحة وتعزيز الأمن الأني المجتمعي، وكذلك تأثير الأزمة على المجتمعات العربية، في إعادة الثقة إلى هذه المجتمعات، ودفعها إلى تعزيز وعيها الصحي واتباع الإجراءات الكفيلة بمواجهة الأزمة ومعالجة آثارها. تعليق على الدراسات السابقة: وكما يلحظ على هذه الدراسات، فإن أكثرها ركز إما لإسات

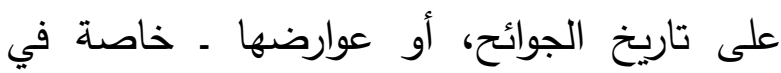

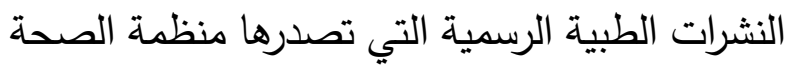
العالمية،. وفي إطار هذا التركيز، دار اهتمام هذه الدراسات على التأثيرات الاجتماعية والتربوية، والاقتصادية لفيروس كورونا. وقد اتخذ أكثرها مناهج علوم التربية في تحديد هذه الآثار. وبالتالي، فإنها اتسمت بطابع تربوي، يعتمد على نماذج تحليلية للاستبيانات والمقابلات الشخصية.

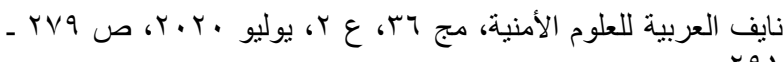
(9) ^ ـ ينظر على سبيل المثال نشرة المعهد الديمقر اطي الوطني: خطة التعامل

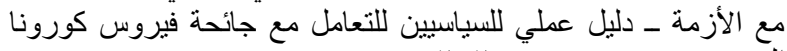

أداة سيطرة على الشعوب الفقيرة، وجعلته في الوقت نفسه أداة نشر للأوبئة الكارثية لا معالجتها.

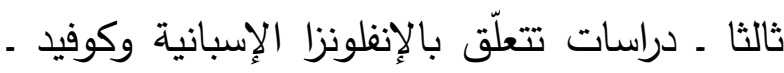
$: 19$ 7 ـ دراسة أمل عبدالفتاح عطوة: التعامل مع الآثار الاجتماعية والاقتصادية لجائحة كورونا COVID 19 في مصر - رؤية مستقبلية' : تتناول الدراسة الآثار الاجتماعية والاقتصادية لجائحة كورونا في إطار رؤية مستقبلية لعوامل الأزمة ومحدداتها الرئيسة. وقد استخدم البحث عدة موجهات وأداة قياس ـ مقياس ليكرت الخماسي ـ لتحديد آثار الجائحة وطرق التعامل معها في المستقبل. وقد توصلت الدراسة إلى عدة نتائج، من أهمها تأثير الجائحة الثديد على الأسر

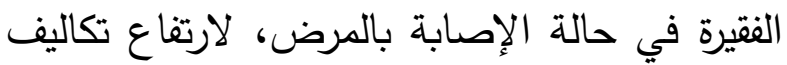

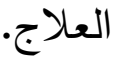
وقد رأت هذه الأسر أنه من الضروري في المستقبل إتاحة تعليم الكتروني للوالدين وتركيز وسائل الإعلام على تقديم الوعي الصحي، وتقديم مساعدات مالية

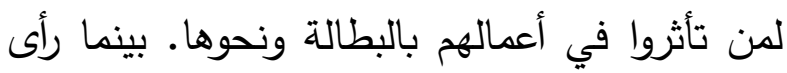

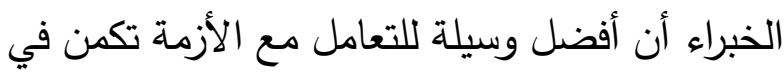
تطبيق الإجراءات الاحترازية، وتعزيز شبكة الأمان

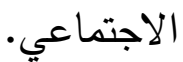

" ـ أمل عبدالفتاح عطوة: التعامل مع الآثار الاجتماعية و الاقتصادية لجائحة

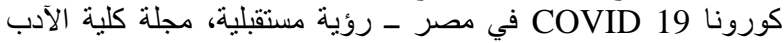

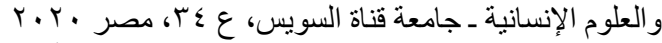

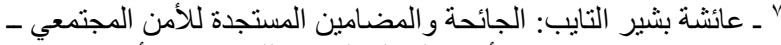
قراءة في مسار ات إدارة الأزمة المجلة العربية للار اسات الأمنية، جامعة لإنة 
انعدام المرض أو العجز". (9) أما المرض؛ فهو عرض يصيب الإنسان قد يتعافى منه، وقد يترك فيه أثرا جسديا أو نفسيا، وإذا تخطى المرض دائرة الأفراد وانتشر بشكل عشوائي وسريع فإنه في هذه الحالة يصبح جائحة' '. جاء في المعجم الوسيط: الجائحة

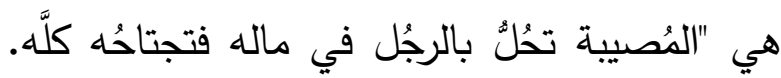
والجائحة في اصطلاح الفقهاء: ما أَذهب الثمرَ أَو فئه بعضَه من آفقة سماوية. ويقال: سنة جائحةُ: جَدبةُة. والجمع: جوائح"('). والجائحة تفشٍ للمرض واتح وانتشاره بسرعة من خلال التواصل البشري، مما يساهم في إصابة أعداد كبيرة

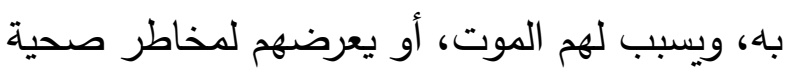

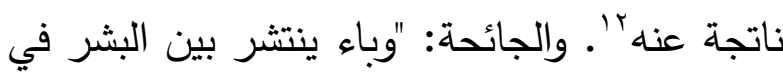

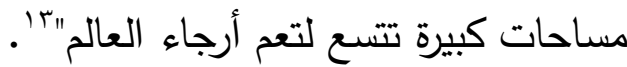
ولقد ظهر كثير من الجوائح عبر التاريخ، منها:

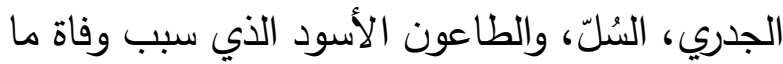

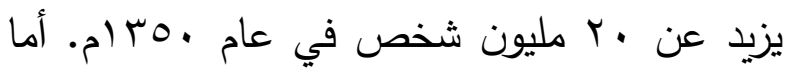
في العصر الحديث، فقد ظهرت جوائح، من أشهرها: والإنفونزا الإسبانية، وجائحة إنفونزا الخنازير 9 . . ؟، وفيروس الإنفلونزا H1N1، وفيروس كورونا

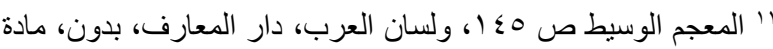

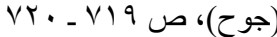
'ا' - ينظر صائشة بشير التايب، الجائحة والمضامين المستجدَّة للأمن

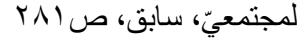
ال' - ينظريّ عائشة بشير التايب، الجائحة والمضامين المستجدَّة للأمن

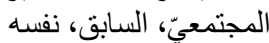

وهذا يعني أن هذه الدراسات لم تقترب من موضوع هذه الدراسة الذي يتناول طبيعة وسائل التواصل الاجتماعي أثناء الجوائح. ومن ثم، فإنني آمل أن تكون هذه الدراسة إضافة لما جاءت به تلك الدراسات.

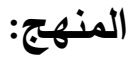

وكما أوضحت في المقدمة، فان هذا البحث ينقسم قسمين رئيسيين: الإطار النظري، والإطار العملي. وتحت كل قسم مجموعة من العناوين التي تستوفي موضوع البحث وأفكاره. والأساس في هذا التناول هو الاعتماد على المنهج الوصفي ـ من ناحية ـ وذلك لتوصيف الإطار العام للظاهرة المتعلقة بالجوائح الكبرى عامة، وبجائحتي الإنفلونزا • ب 9 ام، وكوفيد 9 (، · • • م. وفي الناحية المقابلة، استخدمت مع التوصيف المقارنة، التي تهدف إلى بيان الفروق العملية بين الجائحتين؛ خاصة فيما يتعلّق بالتواصل الاجتماعي كظاهرة إنسانية، يهتم بها هذا البحث. وبالتالي، فإن منهي في تتاول هذا الموضوع هو المنهج الوصفي المقارن.

$$
\text { المبحث الأول ـ الجوائح وتاريخها: }
$$

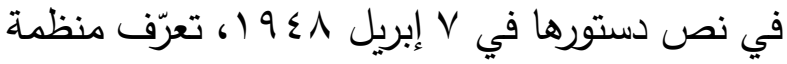
الصحة العالمية الصحة بقولها هي: "حالة من المعافاة الكاملة بدنيا وعقليا واجتماعيا، لا مجرد

9 رودولفو سار اتثي ، علم الأوبئة مقدمة قصبرة جدا ترجمة أسامة فاروق

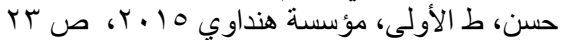

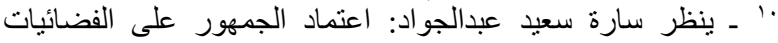
المصرية ومو اقع التواصل الاجتماعي كمصدر لتعزيز التواني الوعي حول جائحة

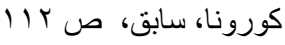




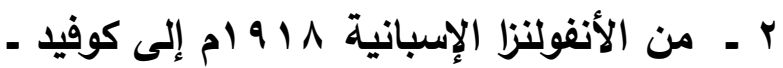

$$
: p^{r} \cdot r \cdot / 19
$$

على أنه من أخطر الجوائح التي مرت بالبشرية، الجوائح المرتبطة بالأنفولنزا، فهي متعددة، وكثيرة

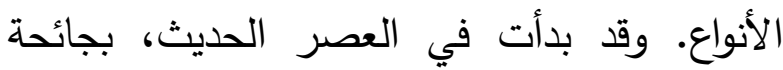
الأنفلونزا الإسبانية، أو ما سُّتيَ بجائحة أنغلونزا عام

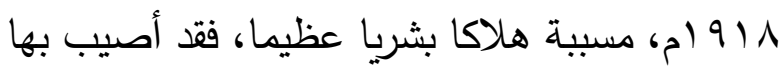
. . . مليون فرد حول العالم، وكانت سببا في وفاة

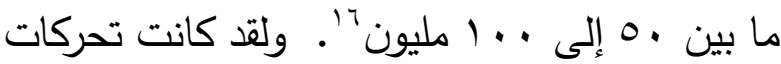

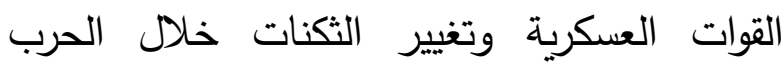
العالمية الأولى سبب انتشار وتحور المرض بشكل

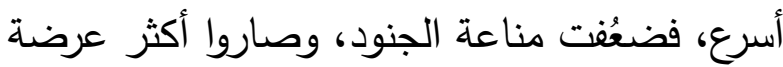
للإصابة بالإنفونزا لأسباب، مثل: الإجهاد وسوء

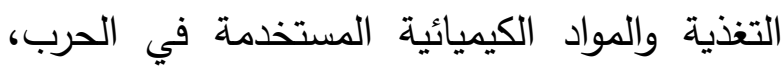
إضافة إلى تحسُن نظم النقل الذي أسهم في تسهيل

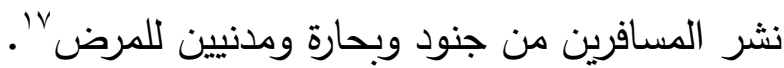

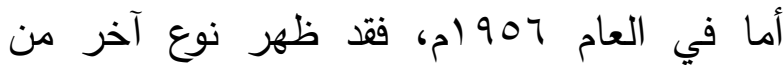
الإنفلونزا، سُمّيت بإنفلونزا آسيا، وسببها فيروس H2N2 وبعده ظهر نوع آخر من فيروسات الإنفلونزا، سمي لـي

ـ ـ ينظر أوسكار جوردا، الجو ائح وتداعياتها الاقتصادية المطولة، مجلة

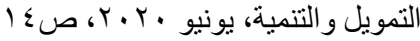

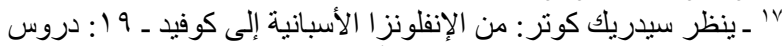

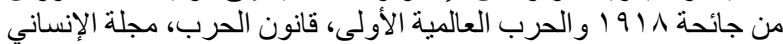
ـ ـ مجلة تصدر عن المركز الإقليمي للإعلام ـ اللجنة الدولية للصليب الإني

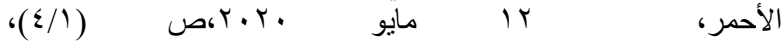
/https://blogs.icrc.org/alinsani/2020/05/12/19-1918 ^^ ـ ينظر أوسكار جوردا، الجو ائح وتداعياتها الاقتصادية المطولة، سابق،
SARS-CoV-2

ومخاطر الجوائح ليست وقفا على البشر، فقد تئثر على البيئة والكائنات الزراعية من ماشية ومحاصيل

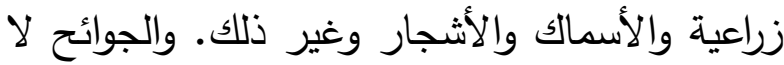
تأتي فجأة، فهي تمر عبر مراحل، تمثّل دورة للجائحة،

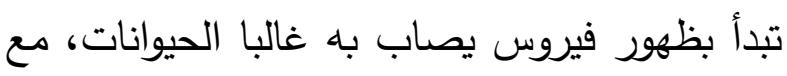

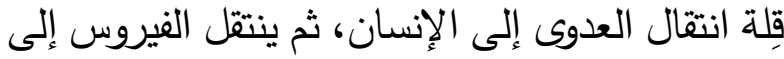
الإنسان من خلال الاتصال بين الإنسان والحيوانات المصابة، ثم تبدأ مرحلة انتقال المرض بين البشر من الإن الإنسان وان فرد إلى آخر مباشرة، فيتحول إلى جائحة مع انتشاره

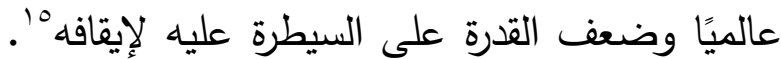

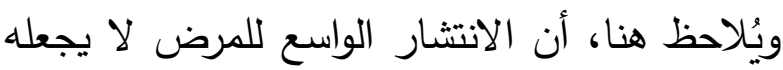
مصنّفا ضمن الجوائح، وإنما طبيعته المُعدية التي لهاني تجعله ينتقل من شخص لآخر ؛ وبسرعة، هي التي

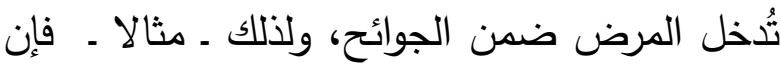
السرطان الذي يتسبب في وفاة الكثيرين حول العالم، رغم خطورته وتأثيره على الإنسان، إلا أنه بسبب كونه

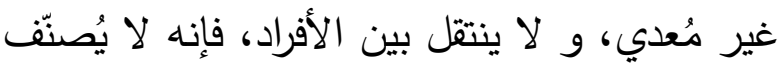
ولا يدخل في دائرة الجوائح.

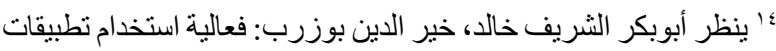

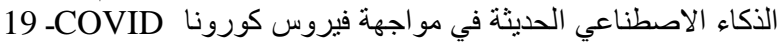

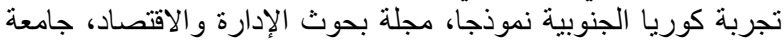

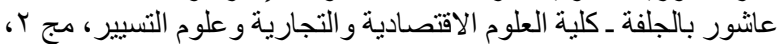

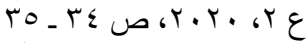

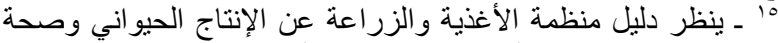

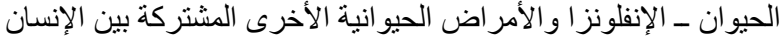

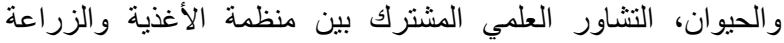

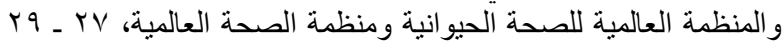

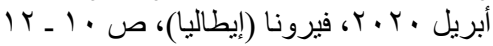


r . الأثر الاجتماعي والاقتصادي للجوائح: مع انتقال البشر وسفرهم بالسفن والقطارات البرات والطائرات، يعمل التواصل الاجتماعي على انتشار الأوبئة، من خلال هذا التتقل المستمر، والتحركات

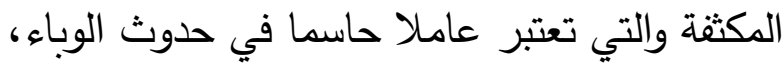
" فقد نشر التجار، والعمال، المهاجرون، والحجاج، لعال والجنود، والرعاة، والعاهرات الأوبئة على ساحة واسعة العها من العالم، [ آخذين ] معهم نماذجهم المرضية ونشروا أمراضهم إلى آخرين، كما اكتسبوا أمراضا جديدة"(rr(). هذا بالإضافة إلى دور الحروب الكبرى ـ خاصة في العصر الحديث ـ إذ قدمت مساهمة كبيرة في انتقال الأمراض وتحولها إلى أوبئة عالمية، ، كما في الطاعون الأسود، والإنغلونزا الإسبانية. ولقد أثرت هذهائ عالمية،

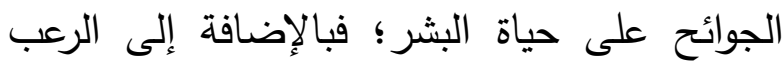

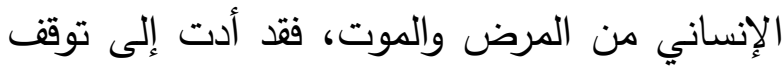
حياة البشر، وسببت خسائر هائلة وشلا في اقتصاد الدول، وما يشبه ركودا في الاقتصاد العالمي؛ مخلفة ونسي

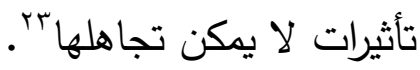
ومن ثم، فللجوائح أثرها الواضتح على تركيبة المجتمع لهائح الذي تظهر فيه، وتؤدي لعواقب وتداعيات خطيرة،

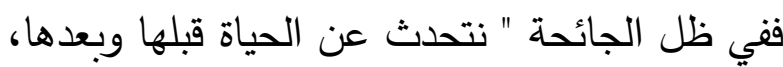
فقد أصبحت محكّا للفهم والتحليل والتفسير بل التنبؤ بأساليب التعامل في الجوانب الاجتماعية والاقتصادية بور ـ ينظر كوين بوستينز، دليل عملي للسياسيين للتعامل مع فيورس

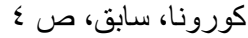

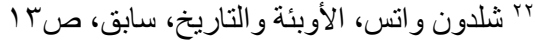

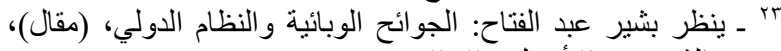

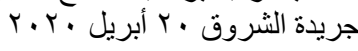

بإنفلونزا الخنازير H5N1 الذي هو مزيج غير مسبوق من فيروسات إنفلونزا الخنازير والطيور والبشر (19). ولقد تم تقصي فيروس إنفلونزا الطيور ، في فبراير عام

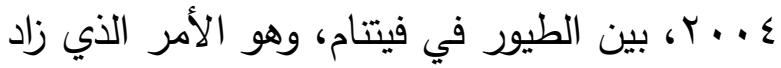
المخاوف من ظهور سلالات متعددة جديدة، إذ إن من المخيف أن فيروس إنفلونزا الطيور ، إلى جانب فيروس إنفونزا البشر ـ الذي يصيب البشر أو الطيور-

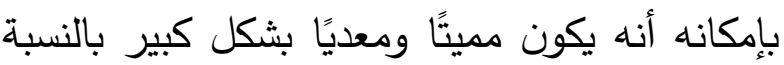
للبشر •(r.) ولقد تحققت هذه المخاوف بعد أقل من عقدين، فعاود فيروس الإنفلونزا الظهور في شكله الجديد؛ المعروف

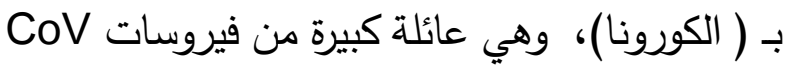
التي تسبب المرض الذي يتراوح بين نزلة البرد

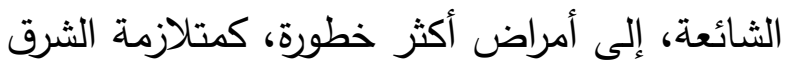
الأوسط التتفية MERS-CoV، والمتلازمة التنفية الحادة الوخيمة SARS-CoV. أما كورونا الموجودة الآن، فهي سلالة جديدة من فيروسات الكورونا SARS-CoV-2، وهي المسؤولة عن هن فئل مرض فيروس كورونا 9 1.r، وتشمل علامات الإصابة: الأعراض التتفسية، الحمى السعال، قصر فرونا النفس، صعوبات في التنفس، وفي الحالات الأكثر شدة يمكن للعدوى أن تسبب ذات رئة ومتلازمة تنفسية

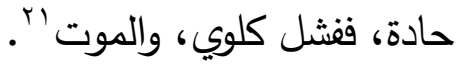

\footnotetext{
19 - ـينظر أحمد عبدالر ازق جبر (إعداد): إنفلونزا الخنازير، كلية الزراعة

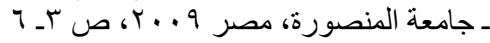

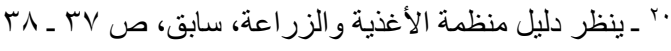


أوروبي من بين كل اثتين، أدى في الوقت نفسه إلى الاعتقاد أن نهاية العالم قد أتت، مع انتشار كبير

$$
\text { لمعتقدات جديدة }
$$

ولقد امتد هذا التأثير إلى القرن التاسع عشر، مع نضج الوعي الصحي، وتقدم المعرفة بالأمراض ومسبباتها الفيروسية والبكتيرية، فظهرت " سياسات جديدة ترمي إلى فرض شروط النظافة، كما وضعت خطط للارتقاء بالصحة العامة وتحسين ظروف السكن - وخاصة سكن العمال - إضافة إلى تسهيل الحصول على الماء الصالح للشرب وتحسين شروط النظافة في المستشفيات، حيث بدأ على سبيل المثل استخدام بعض السوائل في تنظيف وتعقيم المعدات التي تستخدم في الجراحة، وتقرر منع تتويم المرضى في نفس الأسرّة إلا بعد تطهيرها"(·r). وفي القرن العشرين، نما الوعي الجديد بالمرض ومسبباته، فظهرت أول وزارة للصحة في فرنسا، وقد كانت تسمى وزارة النظافة، في "فترة بدأ فيها التفكير في تقوية التعاون الدولي من أجل مكافحة الأمراض والجوائح والأوبئة، وذلك من خلال منظمة عصبة

rrr بشير عبد الفتاح: الجوائح الوبائية والنظام الدولي، (مقال)، جريدة

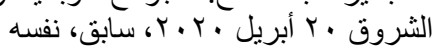

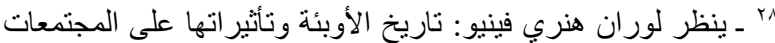

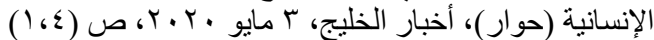

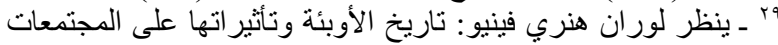

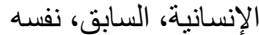

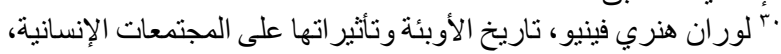

للبشر في ظل المجتمعات الإنسانية "(گ؟). ويأتي في مقدمة هذه الآثار : " إحداث حالة من الهلع والخوف والقلق بين كل أفراد الشعوب، وتغيير أنماط الحياة والعلاقات الاجتماعية"(م). وقد تجدر الإشارة في هذا المقام إلى دور الجوائح الكبرى في حياة الإنسانية، حيث أثّرت تأثيرا مباشرا على الأنظمة الدولية السائدة في حينها، فأدت إلى انهيار تلك الأنظمة، بما في ذلك امبراطوريات قوية، ودول ذات تاريخ طويل في النظام السياسي العالمي بr. وقد لاحظ الباحثون في هذا الثأن، ومن منظور حضاري ـ مثالا ـ أن وباء الطاعون أدى " إلى إضعاف الكنيسة الكاثوليكية، بعدما عرى فشلها فى التصدي له، ما أسفر عن اهتزاز إيمان الناس بدور الكنيسة ورجال الدين، وعجل بانطلاق موجة الإصلاح الديني البروتستانتي من سويسرا وألمانيا في القرن السادس عشر "(rV). وعن التأثير المباشر للجوائح على حياة الناس، اجتماعيا واقتصاديا، فقد أوضح "لوران هنري فينيو"، في حوار، أجرته معه جريدة لوموند الفرنسية، أثر الجوائح الاقتصادي والاجتماعي في المجتمعات التي ضربتها هذه الجوائح عبر التاريخ (r^)، فانتشار الطاعون الذي أدى في العام · ع ا إلى وفاة شخص

\& r أمل عبد الفتاح عطوة، التعامل مع الآثار الاجتماعية والاقتصادية

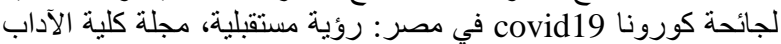

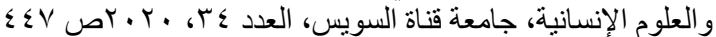

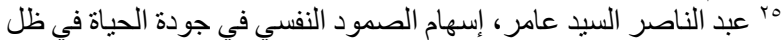

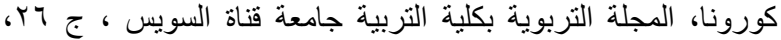

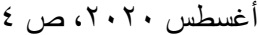

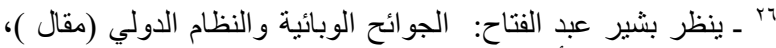

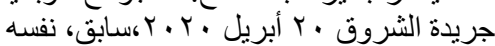


إلى جانب ما شهده العالم من أزمات اقتصادية، "أشد

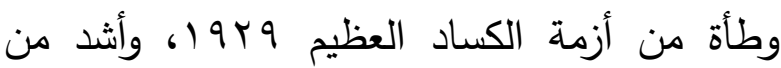
الأزمة المالية العالمية ^ ـ . . التي قيل إنها لا تحدث

$$
\text { إلا كل مائة عام"(بr"). }
$$

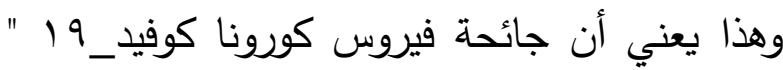
أثرت سلبا على جميع القطاعات الحيوية في

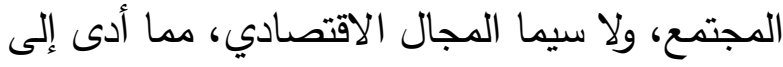
ارتفاع نسبة البطالة وانخفاض متوسط دخل الأسرة والاعتماد المطلق على التكنولوجيا في المجالات التعليمية والوظيفية والاقتصادية"(YV).

المبحث الثاني ـ التواصل الاجتماعي والجوائح بين الإنفلونزا الإسبانية وكوفيد 9 1:

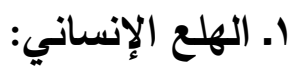

من نافلة القول إن فيروس الإنفلونزا من أخطر الآفات

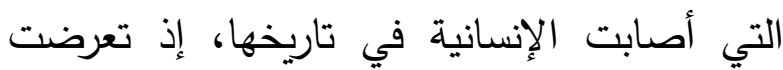
البشرية لثلاث جوائح كبرى بسبهها، خلال الثلاثمائة

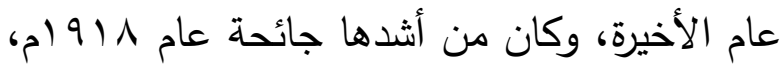

گُ ـ أمل عبد الفتاح عطوة، التعامل مع الآثار الاجتماعية والاقتصادية

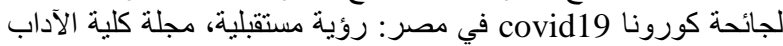

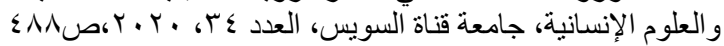

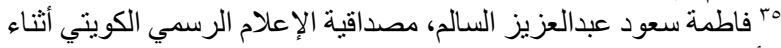

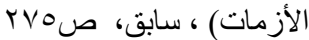
ب أمل عبد الفتاح عطوة، التعامل مع الآثار الاجتماعية والاقتصادية

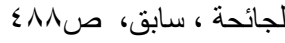

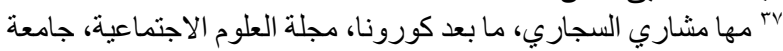

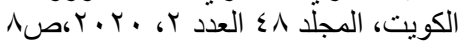

الأمم التي نشأت في العشرينيات" ("(r) لم تعمّر طويلا، قبل أن تتشأ على أنقاضها الأمم المتحدة. وخلافا للجوائح التي ظهرت في حياة الإنسانية، سواء ما سبيته البكتيريا أو الفيروسات، وصاحبت فروبات حروبها

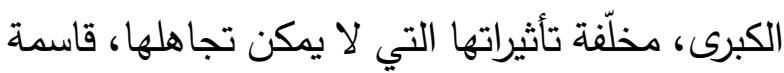
ظهر الإنسانية طيلة تاريخا المنقضي، " تدهم جائحة كورونا عالمنا غير مواكبة لحروب عظمى أو أزمات

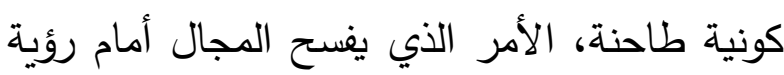

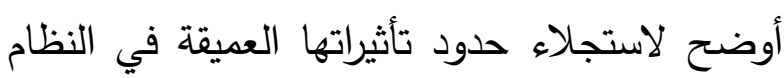

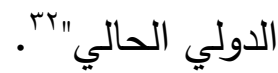
ولقد صاحب ظهور كورونا وانتشارها، تأثير عالمي، ظهر في " كافة مناحي الحياة الاجتماعية والعملية والاقتصادية وطريقة التناعل والتعاطي مع وسائل الإعلام في ظل انتشار الوباء عالميا وتزايد أعداد

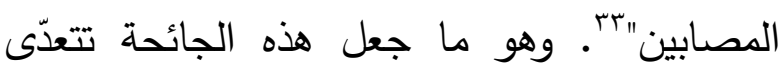
بتأثيراتها الجانب الصحي " إلى مجموعة أزمات

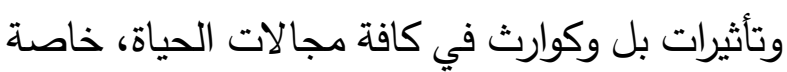

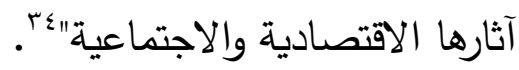
وفي ظل هذ التأثير "أصبحت المعلومات والأخبار جزءًا أساسيا في حياة الناس للاطلاع على الإجراءات الحكومية وآخر تطورات الفيروس وطرق علاجه"(ror)،

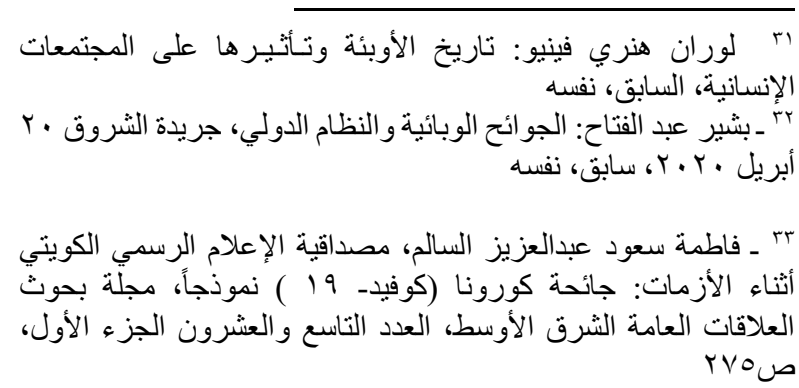


وينتمي إلى جماعة؛ تعرفها ماري دوجلاس بأنها

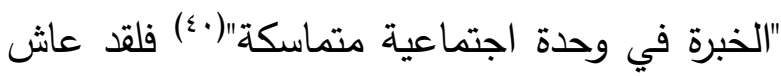
الإنسان قديما في جماعات بشرية: العائلة، القبيلة،

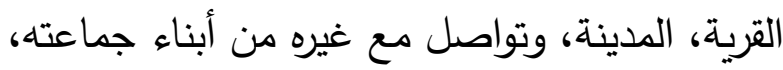

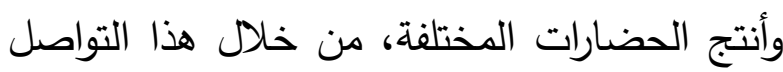
بأثكاله المتعددة: اقتصاديا، وأدبيا، وعلميا، وغيرها. من هنا؛ فإن التواصل الاجتماعي مقياس لكيفية

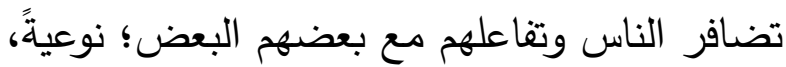
وعدد العلاقات التي تربط الفرد بالآخرين في الدائرة

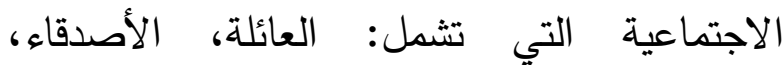
والمعارف. كذلك يتضمن التواصل الاجتماعي

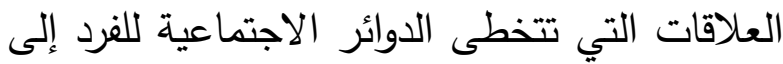
المجتمع كله، وإلى المجتمعات الأخرى. ومن ثم يمثل التواصل أحد عوامل التماسك في المجتمع(1). ومما يساعد الفرد في تفاعله وتواصله الاجتماعي مع

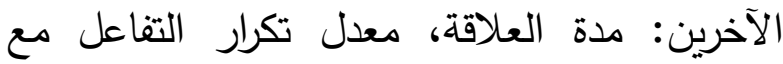

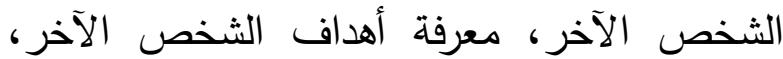

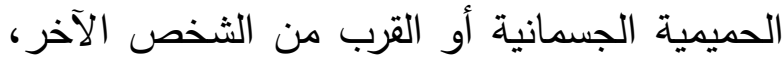

• • مجمو عة من الكتاب: نظرية الثقافة، ترجمة د. على سيد الصاوي، عالم

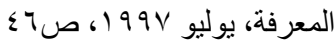

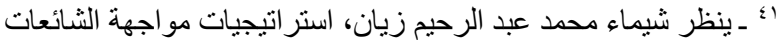

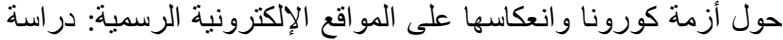

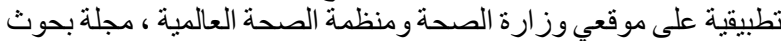

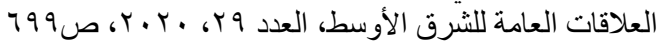

التي مات بسببها ما يقارب •0 إلى ... مليون

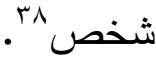
أما كوفيد ـ9 1، والذي نعيش ظلاله منذ أكثر من عامين، فهو آخر هذه الجوائح، في سلسلة فيروس

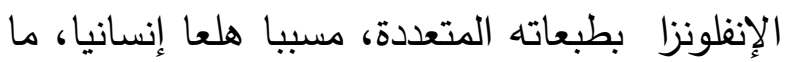
زالت آثاره مستمرة، حيث "شعر بعض أفراد المجتمع بالرعب والخوف والثزع، فلجأ إلى الانخراط في تطبيق الإجراءات الاحترازية، وتتفيذ ضوابط التباعد

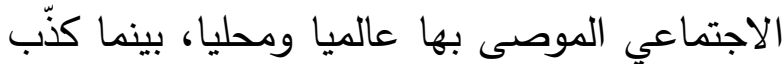
بعض آخر ما يُبث وُيذاع عبر وسائل الإعلام، مؤكدًا أن فيروس كورونا مؤامرة من دول كبرى لتحقيق

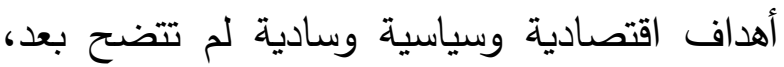
ورغم أن هذه الرؤية بدأت في الانحسار إلا أنها ما زالت قابعة في أذهان بعض الجماهير حتى المتعلمين منهم"(

وهذا يدعونا إلى التأمل في مفهوم "التواصل الاجتماعي" وعلاقته بانتشار الفيروس، ثم علاقته بمعالجة آثار الانتشار ، ضمن استراتيجيات واضحة لمواجهة الأزمة التي تسببها الجائحة. r. التواصل الاجتماعي في حياة البثر: إذا جاز أن نطلق تعريفا للإنسان؛ فمن الممكن القول بشيء من التعميم: أنه كائن اجتماعي ذو تاريخ،

^^ ـ ينظر سيدريك كوتر: من الإنفلونزا الأسبانية إلى كوفيد ـ 9 1: سابق،

ص ( ) (

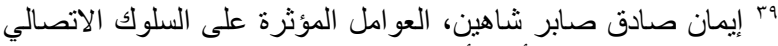

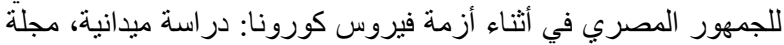

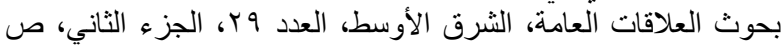


أشكالها، لأهداف مختلفة؛ منها التجارة والعمل وحتى

$$
\text { التزاور بين الأقارب والأصدقاء ج؛. }
$$

وما أعنيه في هذا البحث يشمل هذه الدلالات المجتمعة لمفهوم التواصل الاجتماعي؛ إذ إن إن الاتصال المباشر بين البشر ـ كما سوف أوضح ـ هو المسؤول المباشر عن انتشار الجوائح، في مقابل استخدام (وسائل التواصل الاجتماعي الالكترونية ) أداة رئيسة من أدوات حصار الجائحة ومعالجة آثارها

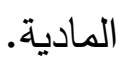

وهذا يعني ـ كما قد نلحظ ـ أن مفهوم التواصل الاجتماعي يعمل في خط واحد متعارض الطرفين، ويشكل ثنائية مادية ذات تأثير مباشر على حياة الناس، في زمن الجوائح خاصة.

\section{r ـ المسؤولية الاجتماعية والإجراءات الصحية في \\ زمن الجوائح:}

كان لانتشار الجوائح في المجتمعات الإنسانية تداعيات خطيرة، جعلت البشريـة تقف صفا واحدا محاولة التصدي لهذا الرعب المميت الذي يضرب الإنسان، "فالمسئولية الاجتماعية هي نظريـة أخلاقية تقترح أن أي كيان ، سواء كان منظمة أو فردا، يقع على عاتقه العمل لمصلحة المجتمع ككل، فالمسئولية

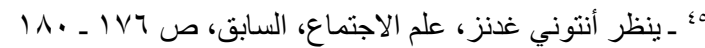

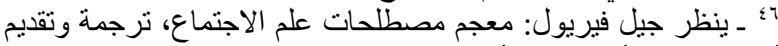

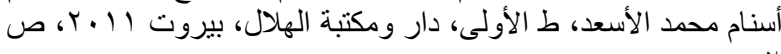

الكشف عن الذات للشخص الآخر ، والدراية بالشبكة

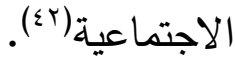

وعلى رغم ما يمثله التواصل الاجتماعي من أهمية ـ كمكون بشري ـ في نقل المعرفة وأنماط الحضارة والصحة النفسية للفرد والجماعة، فإنه يعد خطرا جدا على الفرد والجماعة البشرية في حال انتشار عدوى مرضية أو جائحة؛ لما له من أثر كبير وفاعل في نشر المرض بسرعة كبيرة، إذ أن التاريخ الإنساني يسجل جوائح مدمرة مرت بالبشرية مثل: الطاعون الأسود، الكوليرا والإنغلونزا الإسبانية، وآخرها جائحة

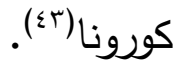

وإذا كان هذا البحث يتتاول أثر التواصل الاجتماعي وخطره على البشر ، ودوره في نقل عدوى المرض وقت تفشيه، في الجوائح الكبرى، فإن من الضروري الانتباه إلى ما يعنيه مفهوم التواصل الاجتماعي بمعناه الواسع، فهو يشمل في الاصطلاح المواقع والتطبيقات الالكترونية التي يستخدمها الناس في عمليات الاتصال اليومي؛ صوتا وصورة؛؛ لكنه أيضا يشير إلى الأصل؛ أي إلى عمليات التفاعل

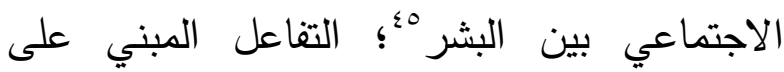
النشاطات اليومية للإنسان، والتي تتطلّب التحرّك من الت مكان إلى مكان، واستخدام وسائل مواصلات بمختلف

r؛ - ينظر نجوى عميرش، الطلبة الجامعيون بين القيم السائدة والقيم

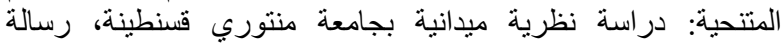

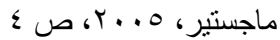

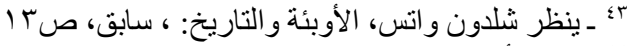

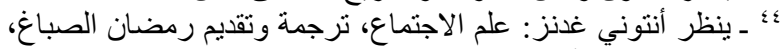

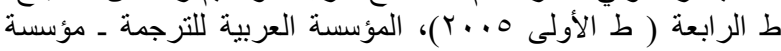

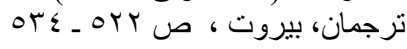


حلول طبية لمعالجة الفيروس أو البكتيريا المسببة له. ويتصل بذلك نمط الاستجابة لهذه الأوبئة في كل المجتمعات الإنسانية، قديما وحديثا، ولذلك طورت هذه المجتمعات الإجراءات والنظم الكفيلة بالتعامل الصحيح مع الوباء. وتاريخيا، بعد "كارثة الطاعون الأولى في أوروبا عام عV للحد من انتشار الطاعون، وبحلول عام •0ء1 م طبقت مدن الشمال الإيطالي الحجر الصحي بإجراءاته الخمس وهي : ــ تحديد انتقال البشر باستخدام الحجر الصحي. اـ دفن إجباري للموتى بالطاعون في حفر خاصة وتغطيتها بالجير الحي، والتخلص من متعلقاتهح الشخصية. ـــ عزل المرضى بالطاعون في مستشفيات الأمراض المعدية. عـ فرض ضرائب من قبل الوحدات المحلية لتقديم خدمات صحية. 0 ـ تقديم المعونة لهؤلاء الذين تضررت حياتهم بالوباء "(9 ). ويمكن أن نلمح فيما سبق تأثيرا مباشرا على نمط الحياة الإنسانية، من خلال تحسين نظام الحياة نفسه، بما يشمله من إجراءات صحية واقتصادية، بهدف مواجهة الوباء مواجهة ( علمية ) أو شبه علمية، ومنظمة تنظيما اجتماعيا خاصا، في ظل إدارة سياسية للأزمة المرتبطة بوجود الوباء، وذلك انطلاقا

على مستوى الوطن العربي، جمعية الاجتماعيين في الثارقة، مجلد VTr،

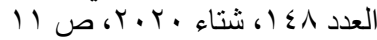
9؛ شلدون و اتس، الأوبئة و التاريخ: المرض ولاء والقوة والإمبريالية، سابق،
الاجتماعية هي أمر يتعين على كل منظمة أو فرد الالتزام به للحفاظ على التوازن ما بين الاقتصاد التهاديه والنظم البيئية والاجتماعية، والمسئولية الاجتماعية ليست وليدة اليوم بل هي ثقافة أصيلة في الإنسانية، فالإنسان مسئول ومكلف عن كل شيء جعل الله له سلطاناً عليه ، أو قدّره على التصرف فيله بأي وجه من الوجوه، سواء كانت مسئولية شخصية فردية أو الو

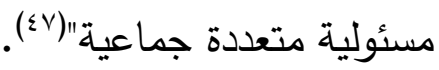
وبالتالي، إذا كانت المسئولية الاجتماعية نظرية أخلاقية، فقد وجب أن تكون التوعية الصحية أمرا ضروريا، "وبما أن التوعية الصحية ونشر الوعي الصحي أمر ضروري لرفع مستوى الصحة العامة

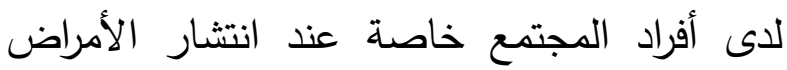
والأوبئة (كما هو الحال في أزمة كورونا) فقد اعتبره

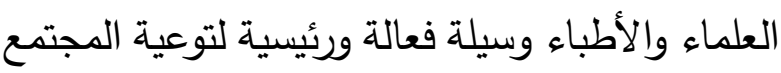

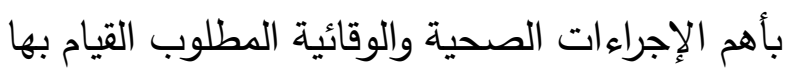
عن طريق وسائل الإعلام التي تمتلك القوة الهائلة في

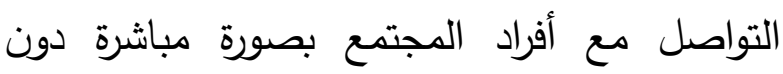

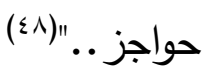
وفي هذا الإطار، عملت المجتمعات الإنسانية على

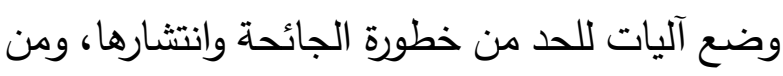
ذلك: الحجر الصحي للمصابين بالجائحة، وعدم السفر من وإلى الأماكن المصابة، كذلك التفكير في بالجي

لاء إبر اهيم محمد الصياد، سلوى محمد الجريتلي، أثر المسئولية الاجتماعية

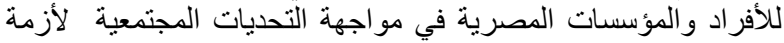

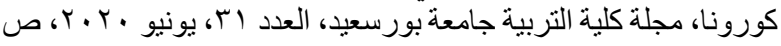
أفر اد المجتمع حول أزمة فيروس كوفيد_ 
تفشي جائحة فيروس كورونا قبل أن تلحق بهم العديد من الدول الأخرى، بما في ذلك الولايات المتحدة الأمريكية، وهو ما يعيدنا أيضا إلى تلك العصور التي كانت فيها الإنسانية جمعاء تواجه الأوبئة والأمراض المعدية بصدور عارية من دون أن يكون لديها اللقاحات والأدوية اللازمة لمكافحتها(م). وفي الإطار نفسه، انتهجت معظم دول العالم السياسة نفسها في مواجهة انتشار المرض، فنرضت الإجراءات الصارمة، واتخذت خطوات استثنائية غير مسبوقة، لاحتواء الجائحة وانتشار المرض به. وهنا كانت الحاجة إلى وعي المجتمع نفسه، وهو أمر صعب، "فالحشود البشرية تتحرك بقناعات شخصية مدفوعة بغريزة البقاء دون أي اعتبار للخطر الحقيقي أو لتعميمات السلطات"ءه ومع ذلك فقد أظهر طائفة كبيرة من أفراد هذه المجتمعات، "درجة كبيرة من الوعي بأهمية المسئولية الاجتماعية وفهم المضامين الاجتماعية والأخلاقية لهذا الموضوع"(00). ومسألة الوعي الاجتماعي والإحساس بالمسؤولية الاجتماعية ودورهما في مواجهة الجائحة ومنع انتشار المرض، تبرز مسألة في غاية الخطورة، وتلك هي دور التواصل الاجتماعي؛ إذ إن الجوائح التي تفشت في المجتمعات البشرية كان لها مردود هائل على بنية تلك المجتمعات وأثرت فيها بالسلب والإيجاب حيث

r م ينظر إبر اهيم محمد الصياد، سلوى محمد الجريتلي، أثر المسئولية

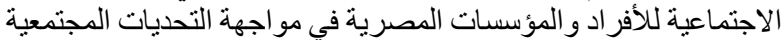

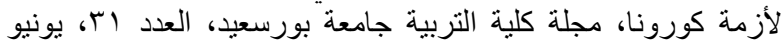
IVT

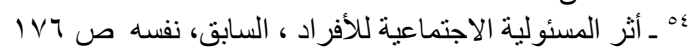

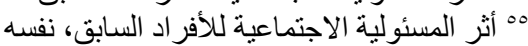

من الاعتقاد أن احتياجات المرضى واحتياجات المجتمعات المتأثرة بالجائحة يجب أن تكون لها الأولوية، ضمن إجراءات مواجهة ومعالجة الأزمة، فالاستجابة السريعة، والإجراءات الصحيحة، يمكن أن تؤثّر تأثيرا مباشرا على أعداد المرضى ونوعياتهم، و "كثيراً ما يتطلب تفشي الوباء انتشارا سريعا وكبيرا للخدمات اللوجيستية التي يمكن أن تتراوح بين وضع مرافق مؤقتة لعلاج المرضى، أو تحسين المياه والصرف الصحي للمساعدة في منع انتشار (المرض" (0.). وتاريخيا أيضا، يمكن أن نلاحظ أن القرون الوسطى في زمن الأوبئة شهدت عددا كبيرا من هذه الإجراءات المبنية على فرض الحجر الصحي، وإغلاق الفنادق ومنع الجنائز • وهو ما ادى في نهاية المطاف إلى أن يعتمد بالموافقة والتنفيذ " السياسيون والتجار والكثير من السكان ذلك الموقف الذي يختزل الصحة العامة ومكافحة الأوبئة والجوائح والأمراض في المسائل المتعلقة بالنظافة الشخصية، أي أن العيش في بيئة سليمة يكفي كي يقي الإنسان نفسه الأمراض

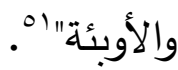
وفي العصر الحديث، مع انتشار جائحة كورونا، عادت المجتمعات الإنسانية إلى تلك الإجراءات القديمة، فقد "فرض الصينيون الحجر الصحي إثر

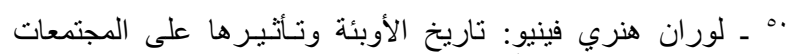

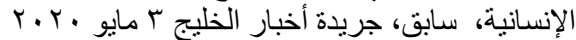

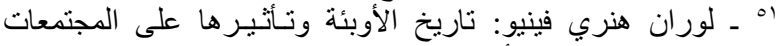

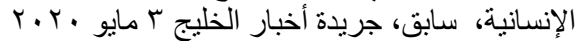

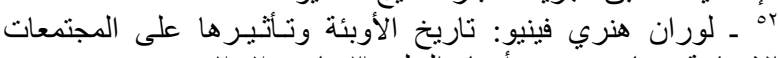

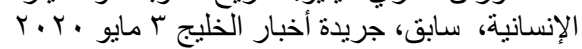


التي تؤدي إلى تبادل الاتصال والتجمّع المنظم

نلأفراد (ov)

وبالتأمل في طبيعة التواصل الاجتماعي، فسوف نجد أن في عصر ما قبل التكنولوجيا الذكية، كان التواصل الاجتماعي سببا مباشرا في نقل عدوى الأمراض، والتسبّب في جعلها جائحة تضرب المجتمعات الإنسانية، في دول وقارات، على نحو ما حدث في جائحة الانفلونزا الإسبانية التي سبب فيها التواصل الاجتماعي للجنود، أثناء الحرب العالمية الأولى، انتشارا للمرض، وجعله جائحة تضرب العالم^ه. وللأسف تكرر الأمر نفسه في عصرنا الحديث، رغم تقدّم وسائل التكنولوجيا وتطوّر الأنظمة الصحية، فقي بداية الأزمة، قبل تتتبه دول العالم وتتخذ الإجراءات الصارمة لمواجهة الأزمة، انتقل فيروس كورونا كوفيد_9 1 من مدينة ووهان الصينية، بسبب كونها مدينة تجارية هامة في الصين، إلى الدول المحيطة، وبسبب التواصل الاجتماعي جعل المرض جائحة عالمية

وهذا يلفتنا إلى حقيقة أن حركة البشر في عصرنا الحالي، تتخذ أبعادا إنسانية كبيرة، إذ تعتمد في تنقلها، على وسائل النقل من السيارات الخاصة، أو القطارات، أو السفن، أو الطائرات، الأمر الذي يسهم في الاحتكاك المباشر بين البشر ؛ خاصة مع الازدحام

9ه ـ ينظر عبدالناصر السيد عامر : إسهام الصمود النفسي في جودة الحياة

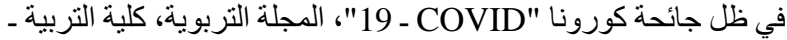

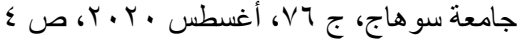

سببت الجوائح رعبا من المرض الذي يحصد الأفراد بلا هوادة ولا رحمة؛ في ظل عجز إنساني للتقليل من مخاطره وتداعياته، وكان للتواصل الاجتماعي في ظل تشي الجوائح خطره العظيم في نقل المرض من مكان لأخر مما يساهم في توسيع دائرة الخطر وأعداد المصابين وكما سبقت الإشارة، فإن أشكال التواصل ظهرت في تحركات الجنود في المعارك وفي الحروب الكبرى مثل الحربين العالميتين الأولى والثانية، وابتكار وسائل النقل الحديثة التي تمثلت في السفن الضخمة، القطارات، والطائرات التي ارتبطت بحركة الاقتصاد الدولي والتجارة بين الدول؛ فأدي ذلك لنقل الأمراض، والحشرات، والبكتيريا، والفيروسات. ولذلك يعتبر التواصل الاجتماعي نقطة إجرائية أساسية في فهم التفاعلات البشرية، وتفسير النصوص والخبرات الإعلامية، وكل طرائق التواصل والاتصال والإرسال، بعد أن أصبح التواصل الاجتماعي نفسه "علما قائما بذاته، وله تقنياته ومقوماته الخاصة وأساليبه المحددة له"ه حيث يهتم بأنساق العلاقات التي تحدث بين الناس داخل إطار اجتماعي معين، أو بين مجموعة أنساق، سواء تم الاتصال بشكل مباشر من خلال اللقاء الشخصي بين الأفراد، أو بشكل غير مباشر من خلال العلاقات الاجتماعية

1ه ـ عيسى بن سليمان الفيفي (إعداد): برنامج التو اصل الاجتماعي، نسخة

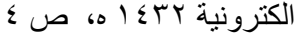

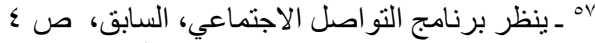

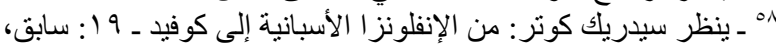

ص) 
ذلك اعتماد مفهوم "التباعد الاجتماعي"، وتقليل السفر أو إيقاف نشاطه إلا للضرورة القصوى، واتباع نهج العمل عن بعد، بما في ذلك اعتماد الدراسة الدانة

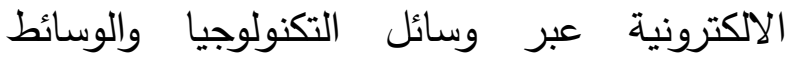
الاجتماعية الحديثة، وتقليل تمضية أوقات الفراغ في

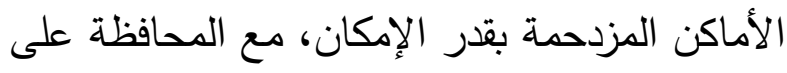
مسافة مأمونة بين الأشخاص الذين ظهرت الإن عليهح أعراض الإنفلونزا أو الأعراض الثبيهة بهآّآ.

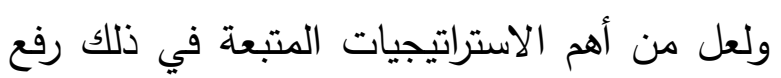
درجة الوعي الاجتماعي بالمخاطر الصحية للفيروس، وطرق الوقاية والعلاج، التي تشمل اتباع قواعد النظافة العامة، إضافة إلى الوعي بالمخاطر والآثار المترتبة على انتشار الفيروس، خاصة في مجال الاقتصاد، كحافز على اتباع هذه القواعد والالتزام

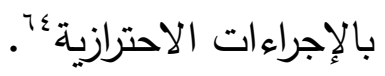
"وبما أن التوعية الصحية ونشر الوعي أمر ضروري لأنرايه

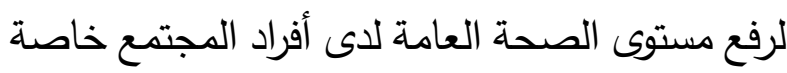

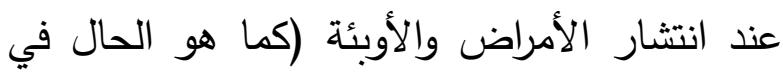

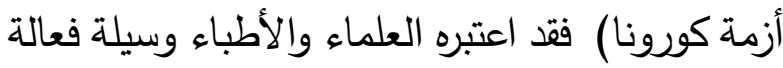
ورئيسية لتوعية المجتمع بأهم الإجراءات الصحية والوقائية المطلوب القيام بها عن طريق بهائ وسائل

مجلة المشكاة في الاقتصاد ـ التنمية والقانون، المركز الجامعي بلحاج

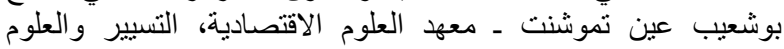

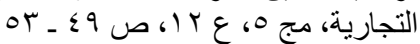
rاب عائثة بثَير التايب، الجائحة و المضامين المستجدَّة للأمن المجتمعيّ،

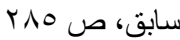
آ" ينظر عائشة بثير التايب، الجائحة والمضامين المستجدة للأمن

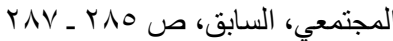

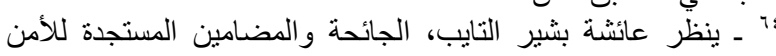

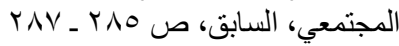

في المطارات والموانئ ومحطات السكك الحديدية، وذلك بغرض التجارة بين الدول أو السياحة أو التعلم

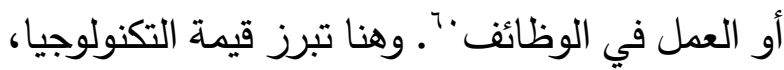
شاملة وسائل الاتصال الحديثة، ومنصات التواصل لتصل

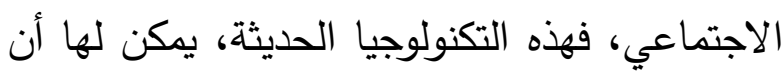

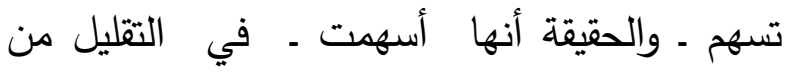

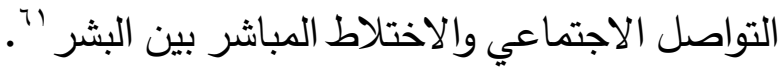
؛. استراتيجيات المواجهة: وأمام هذا الهلع البشري، فلقد صار من حكم البديهي أن الطرق المعروفة المتبعة للحد من انتشار جائحة الإنفلونزا ترتبط أساسا بالسلوك، وبإِادارة

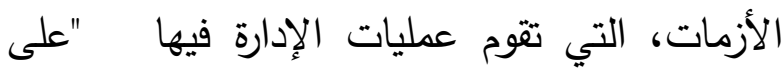

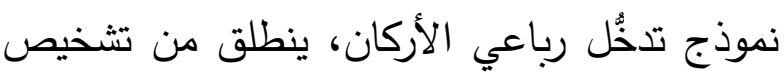
الوضع الراهن وتحديد إشارات الخطر ، ثم يتوجَّه نحو فحص الاستراتيجيات الجاهزة للتدخل، مع اختيار أكثر البدائل كفاءةً في تحقيق نتائج سريعة، ثم التدخُل السريع لمواجهة المخاطر وإدارة عملية التدخل؛ بحيث تحقق أقصى درجة من المنفعة، ثم تأتي أخيرا مرحلة

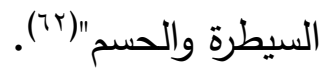
ولذلك فإن الأمر يتطلب استراتيجيات اتصال جيدة، تراعي طبيعة المجتمع وسلوكياته تجاه المرض؛ ومن

“" - ينظر أبوبكر الثريف خوالد، خيرالدين محمود بوزرب: فعالية فئلية

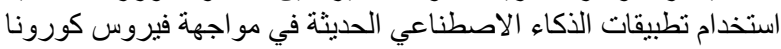
كالية COVID

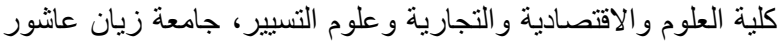

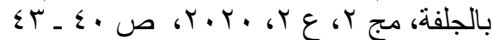

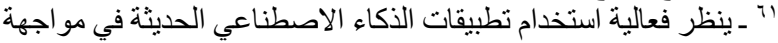

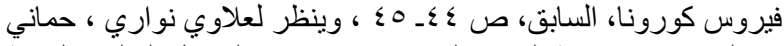

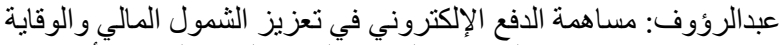

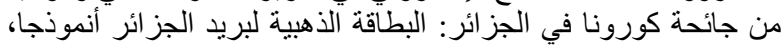


ففي جائحة الإنفلونزا الإسبانية كانت الحرب هي السبب المباشر لانتشار فيروس الإنفلونزا، خاصة مع الع محدودية وسائل النقل الرئيسية ـ بالقياس إلى وسائل النقل الحالية ـ وتركزها في السفن التي حملت الجنود المصابين من قارة إلى قارة، فتسببت في نقل الفيروس من أوروبا إلى الهند فالأمريكتين، فكل أرجاء العالمجابـ. أما كوفيد ـ 9 (، فان السبب الرئيسي لانتقال البشر تمثّل في السفر من أجل التجارة، مع شبكة واسعة من المصالح التجارية التي تُستخدم فيها عابرات البحار الضخمة، لنقل البضائع، إلى جانب الطائرات الحديثة في نقل المسافرين ‘. . ويمكن أن نلاحظ هنا أننا نتخطّى مرحلة انتقال الفيروس من الحيوانات أو الطيور إلى البشر، باعتبارها المصدر الرئيسي للفيروس، فالحقيقة أن انتقال الفيروس من المصدر الأصلي ـ طيورا وحيوانات ـ إلى البشر لا يمثّل في ذاته خطرا، ولا يؤدي إلى حدوث جائحة، وإن كان يشكّل خطرا مباشرا على من يصيبه، وإنما الخطر والجائحة يتحققان ين يتواصل البشر محتكين ببعضهم البعض، أيا كان الغرض الأساسي من هذا الاحتكالك.

وفي مقابل الاحتكالك ـ التواصل الاجتماعي المسؤول عن حدث الجائحة وانتشارها، فان

VY - ينظر فاطمة سعود عبدالعزيز السالم، مصداقية الإعلام الرسمي

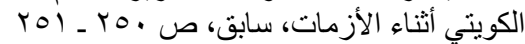

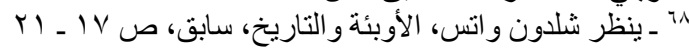

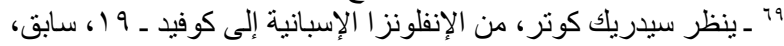
ص ( ) • - ينظر أبوبكر الثريف خوالد، خير الدين محمود بوزرب: فعالية

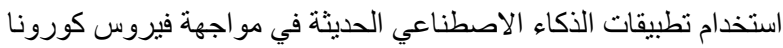
19 ـ COVID
الإعلام التي تمتلك القوة الهائلة في التواصل مع أفراد المجتمع بصورة مباشرة دون حواجز ، خاصة الإعلام الإككتروني الذي ساهم في نجاح وظهور شبكات التواصل الاجتماعي المختلفة والتي سحبت البساط من تحت أرجل الإعلام التقليدي"(ro). وهنا يبرز دور الإعلام في رفع درجة الوعي المطلوبة، بثه المواطنين على الامتثال لاستراتيجيات الحد من انتشار المرض، على أن تقوم بدور إيجابي في استراتيجيات المواجهة، بعيدا عن الشائعات والأخبار الكاذبة(ז7)، ضمانا لبقاء درجة الثقة المطلوبة لدى المواطنين في المسؤولين الحكوميين وفي التدابير التي يُطلب منهم الالتزام بها • التواصل الاجتماعي بين نشر الجائحة ومواجهتها: تبيّن العناوين السابقة في هذا البحث نقطة في غاية الخطورة، ذلك أن التواصل الاجتماعي - بمعنى الاحتكاك المباشر بين الناس، للأسباب المتتوعة التي تدعوهم إلى التنقل ـ السفر ، التجارة، التزاور، الحروب • إلخ . كانت هي السبب المباشر لانتشار الفيروسات، ومن ثم حدوث الجوائح بشكلها الكارثيّ

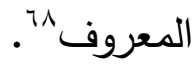

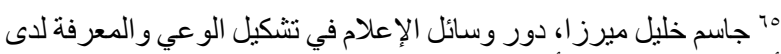

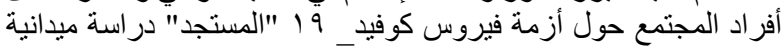

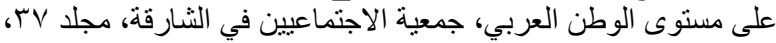

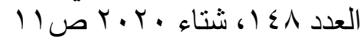

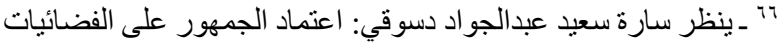

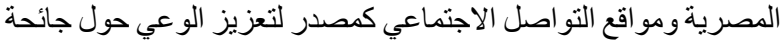

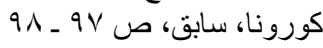


الغباء السياسي لربما أمكن تدارك الكثير من الآثار

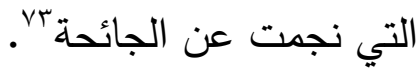
والأمر نفسه يقال بدرجات مختلفة عن دول العالم، فقد تأخرت كثيرا عن اتخاذ القرارات والتدابير الحازمة اللازمة للمواجهة. والثاهد على ذلك أن بلادا مثل هونغ كونغ وماليزيا وتايوان اعتمدت تدابير صارمة في التعامل مع الأزمة منذ بدايتها، فتجنبت الآثار الكارثية لانتشار الوباء، إلى حد كبير ، على الرغم من

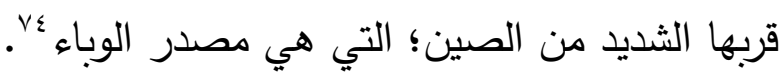
بينما دول أخرى كفرنسا وإيطاليا وإسبانيا وتركيا وإيران، بل والولايات المتحدة الأمريكية، ترددت في المواجهة الحازمة، بين الإعلاق الجزئي والتهاون في تطبيق التدابير الاحترازية، ما أدى إلى انتشار مفزع الجعانه

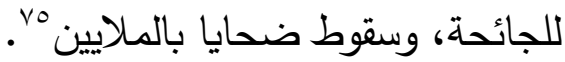
ولذلك عادت هذه الدول ـ ومن بينها دولنا العربية ـ إلى اتخاذ التدابير الحازمة لمواجهة الأزمة، فأغلقت المجال الجوّي ومنعت السفر إلا بشروط قاسية، بل

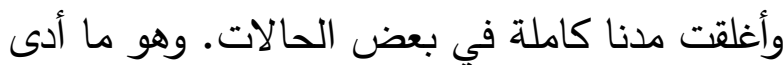
إلى تخفيف آثار الأزمة، رغم سقوط الضحايا بالآلاف، لكن الأعداد التي وقعت ضحية الفيروس التها

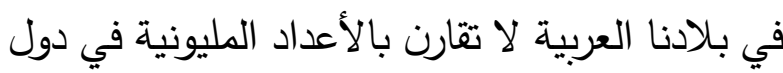

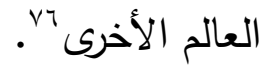

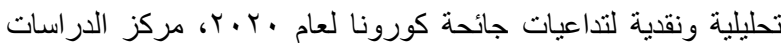

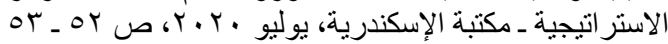

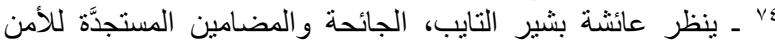

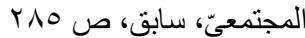

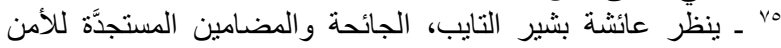

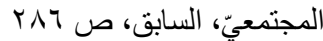

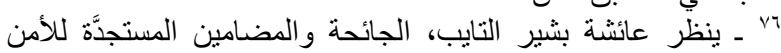

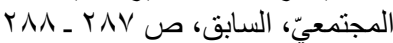

الإجراءات الصحية المستخدمة في كل حالة تمثّل

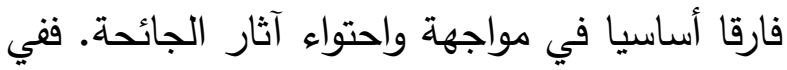
الإنفلونزا الإسبانية، على الرغم من وجود الوعي بالمخاطر الصحية للفيروسات، ومعرفة كثير من

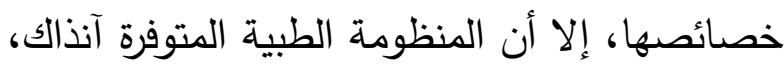

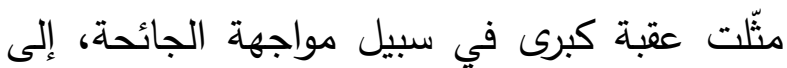

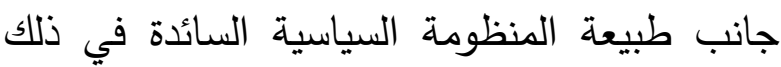
الوقت، فالعالم وقتها كان مازال يعيش تحت ظلال الاستعمار والهيمنة المعتمدة على القوة، إلى جانب الجدل حول مفهوم حقوق الإنسان وحقوق الدول

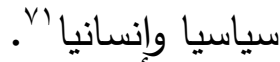
أما كوفيد ـ 9 1، فهي تختلف من الناحيتين: المنظومة السياسية والمنظومة الطبية، فالمنظومة القانونية التي تحكم سياسات العالم تفرض على الدول جميعا الوقوف إلى جوار بعضها البعض في مواجهة الأزمة، بما في ذلك توفير المساعدات الطبية والمعلومات الخاصة باللقاحات المستخدمة في مواجهة

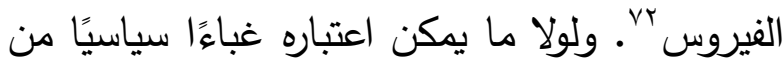
السلطات الصينية التي حجبت المعلومات الرئيسية حول ظهور الجائحة وانتشارها في وقتها، ما أدى إلى لى لرئي

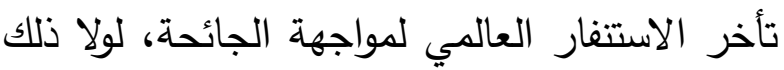

" ـ ـ ينظر سيدريك كوتر ، من الإنفلونزا الإسبانية إلى كوفيد ـ 9 1، سابق، ص (ז/T)

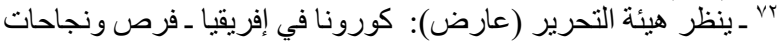

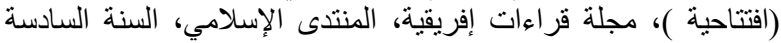

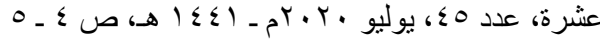

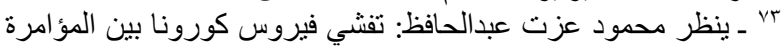
و التعاون الدولي، ضمن: سوزان عابد (تحرير) : تداعيات الجائحة ـ رؤى المى 


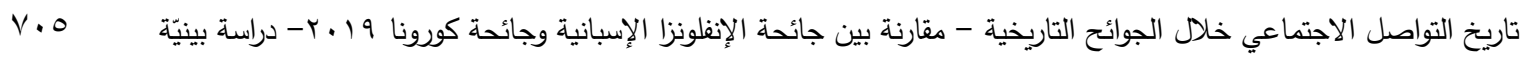

على المسافات الآمنة واستخدام واقيات الوجه التي

تُعدّ من العوامل الرئيسية في مواجهة الجائحة وتكمن قيمة هذه الوسائل إذا ما نظرنا إلى الوراء، زمن الإنفلونزا الإسبانية، فرأينا العزلة الكاملة التي فُرضت على الناس، فالتزموا بيوتهم، أو هجروا مدنهم بعد انتشار الجثث في الشوارع بالآلاف •^. بينما التقدم المذهل في وسائل العلاج ومعرفة خصائص المرض، مكّنت المسؤولين في مواجهة كوفيد ـ 9 1 ، من الدفن الآمن، اللائق للضحايا، رغم أن بداية الأزمة شهدت ارتباكا بسبب الأعداد الكبيرة للضحايا وامتلاء المستشفيات بهم.

وبالتالي يمكن مدا سبق استخلاص الفرق بين الإنفلونزا الإسبانية وكوفيد ـ 9 ا من ناحية علاقة كل منهما بالتواصل الاجتماعي في النقاك التي يعبر عنها الجدول التالي:

ومن جهة ثالثة، يضاف إلى الميزات النسبية التي تحظى بها كورونا ـ 9 1، أن وسائل الاتصالات العالمية شهدت طفرة كبيرة عن مثيلها قبل مائة عام، كورك وهو ما مكّن وسائل التواصل الاجتماعي - مواقع التواصل والإنترنت والفضائيات خاصة ــ مكنها من الإسهام بدور إيجابي واضح في نشر الوعي الصحي والتحذير من مخاطر الفيروس وتعريف الجمهور بالإجراءات الصحية الصحيحة، إلى جانب السرعة الفائقة في نقل المعلومات والاخبار ويضاف إلى ذلك، دور هذه الوسائط في تمكين البشر من الاستغناء بنسبة كبيرة عن الحاجة إلى التنقل،

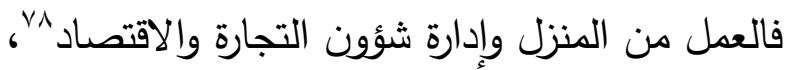
بل والسياسة عن طريق البث المباشر ، جعل التواصل الإنساني وإدارة شؤون الحياة ممكنا، فيما سُميَ بالعودة إلى إجراءات الحياة الطبيعية، مع المحافظة

\begin{tabular}{|c|c|c|}
\hline كوفيد ـ 19 & الإنفلونزا الإسبانية & وجه القارنة \\
\hline التجارة والسفر & الحروب الحرب & سبب الانتشار الرئيسي \\
\hline متوفرة وحديثة & غير متوفرة، وقديمة & وسائل العلاج \\
\hline الاحترازية مكن ومتاح باستخدام الإجراءات & نادر ويصل إلى درجة العزلة & الاتصال بين الناس \\
\hline ما زالت مستمرة & انتهت تاريخيا & المواجهة \\
\hline التسيق قائم ومستمر & التسيق قليل & دور المؤسسات السياسية \\
\hline واسع الانتشار & محدود المكان والزمان & دور المؤسسات الاجتماعية \\
\hline
\end{tabular}

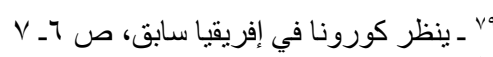
“ ـ ينظر سيدريك كوتر ، من الإنفلونزا الإسبانية إلى كوفيد ـ 9 (1، سابق،

ص ص (
vV - ينظر عائشة بشير التايب، الجائحة و المضامين المستجدَّة للأمن

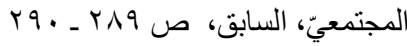

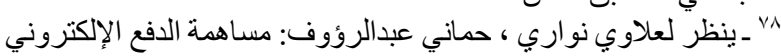

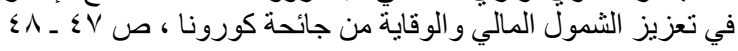




\section{ومن ثم يمكن استخلاص النتائج التالية:}

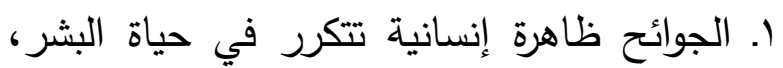

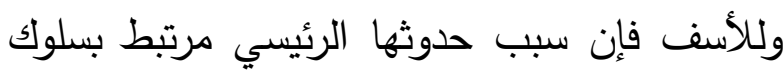

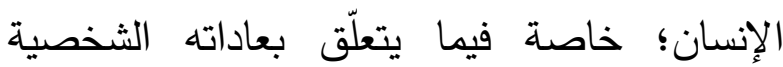
المرتبطة بالطعام وبالصحة العامة. r. وبالتالي، تبرز في ضوه هذه وباه الحقيقة أهمية الدور الذي تلعبه وسائل الإعلام في توفير المعلومات الصحيحة، وفي رفع درجة الوعي لدى الإنسان بالمخاطر التي تسبيها هذه الجوائح، وبطرق الوقاية

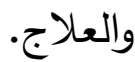

r. كما يبرز دور وأهمية العلم التجريبي ومراكز البحث

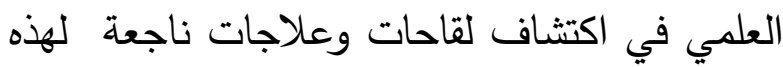

$$
\text { الفيروسات القاتلة. }
$$

ع. كما ييرز في هذا الإطار دور العمل الجماعي بين مؤسسات المجتمع الدولي لمواجهة خطر هذه الجوائح

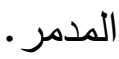
ه. وأمام المخاطر والخسائر الاقتصادية والآثار الاجتماعية التي تسبيها هذه الجوائح، فإن دور وسائل التواصل الاجتماعي والفضائيات يغدو أكثر مركزية وأهمية في مواجهة هذه الآثار ، خاصة مع إمكانية مباشرة العمل والتجارة من المنزل. 7. وإن الأهمية البالغة في سبيل مواجهة هذا الخطر

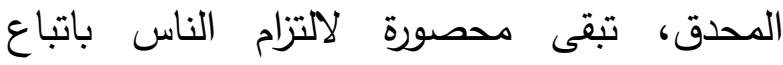
الإجراءات الاحترازية واتخاذ التدابير الصحية في لهرات حياتهم اليومية التي باتت مرهونة بوجود الوباء

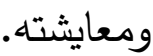

الخاتمة وأهم النتائج: - (المج

حاولت في هذا البحث استقصاء الظروف التاريخية التي أدت إلى انتشار جائحتي الإنفلونزا الإسبانية، وكورونا، خاصة من جهة علاقة هذا الانتشار بالمفهوم الواسع للتواصل الاجتماعي. وقد بيّنت في سياق هذا الاستقصاء مفهوم الجائحة وأثهر الجوائح التاريخية، ووقفت خاصة عن المتصل منها بفيروس الإنفلونزا باعتباره أخطر الفيروسات من حيث التطور والظهور في طفرات مختلفة متجددة ومتكررة عبر التاريخ الإنساني. ثم وقفت عند الآثار الناجمة عن الجوائح، اجتماعيا واقتصاديا، ومن ثم انتقلت إلى مفهوم التواصل الاجتماعي، وبيّنت ما يتعلّق به به من مسؤولية

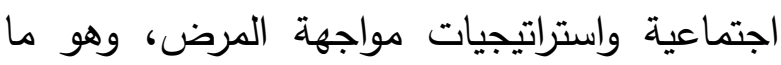
مكنني في الأخير من الوقوف عند الخائص الطبيعية للتواصل الاجتماعي في ظل جائحتي الإنفونزا الإسبانية وكورونا، ومن ثم أمكن استخلاص أبرز الفروق الاجتماعية التي تميّز الجائحتين.

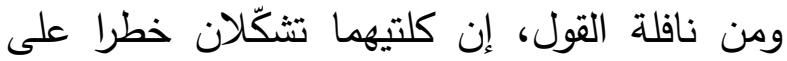
الإنسان، وضحاياهما بالملايين، وأن السبب الرئيسي في حدوثهما هو عمليات التتقل بين البلدان والقارات؛

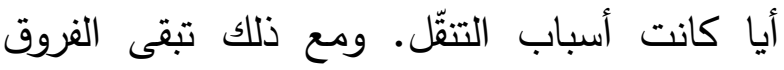
(الاجتماعية ) المتعلّقة بالتواصل أكبر من جوانب دلب لباب

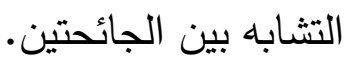




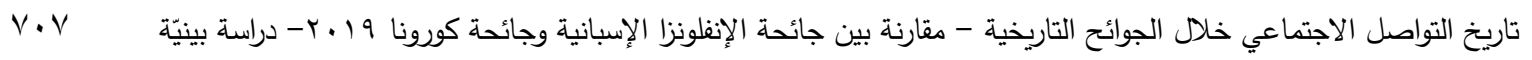

وبعد، فإنني أدعو الله سبحانه أن يحفظ بلادنا وأهلينا بكلية التربية جامعة قناة السويس ، ج جب، أغسطس

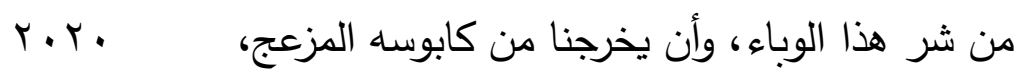
غلى رحابة العيش والاتصال التواصل الاجتماعي اعتماد الجمهور على الفضائيات المصرية ومواقع الآمن والصحيح، راجيا أن يكون ما قدمته في هذا التواصل الاجتماعي كمصدر لتعزيز الوعي حول جائحة كورونا (سارة سعيد عبدالجواد): ، مجلة بحوث العلاقات العامة الثرق الأوسط، ع 9٪، أكتوبر البحث مفيدًا ومضيفًا إلى ما سبقه في المكتبة العربية من بحوث ودراسات. $r \cdot r$. والله تعالى وليّ التوفيق. ـ الأوبئة والتاريخ ـ المرض والقوة الإمبريالية (شلدون قائمة المراجع: واتس): ترجمة أحمد محمود عبدالجواد، مراجعة عماد صبحي، ط الأولى، المركز القومي للترجمة، ع צ ـ التعامل مع الآثار الاجتماعية والاقتصادية لجائحة. كورونا COVID 19 في مصر - رؤيـة مستقبلية (أمل عبدالفتاح عطوة): ، مجلة كلية الآدب والعلوم الإنسانية . جامعة قناة السويس، ع ع ع، مصر $r \cdot r$. ـ التعامل مع الآثار الاجتماعية والاقتصادية لجائحة. كورونا Covid19 في مصر : رؤيـة مستقبلية (أمل عبد الفتاح عطوة): مجلة كلية الآداب والعلوم

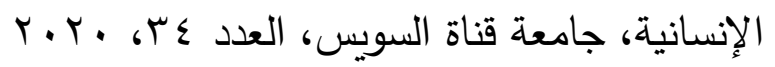
ـ الجائحة والمضامين المستجدة للأمن المجتمعي - إلمان قراءة في مسارات إدارة الأزمة (عائشة بثير التايب): المجلة العربية للدراسات الأمنية، جامعة نايف العربية

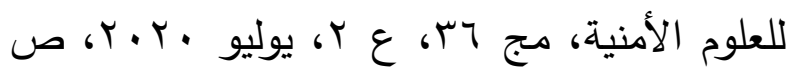
rq1. $r \vee q$ ـ أثر المسئولية الاجتماعية للأفراد والمؤسسات المصرية في مواجهة التحديات المجتمعية لأزمة كورونا (إبراهيم محمد الصياد، سلوى محمد الجريتلي): مجلة كلية التربية جامعة بورسعيد، العدد

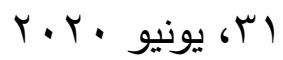
ـ استراتيجيات مواجهة الثائعات حول أزمة كورونا وانعكاسها على المواقع الإلكترونية الرسمية: دراسة تطبيقية على موقعي وزارة الصحة ومنظمة الصحة العالمية (شيماء محمد عبد الرحيم زيان): مجلة بحوث العلاقات العامة للشرق الأوسط، العدد 9؟، $r \cdot r$. - إسهام الصمود النفسي في جودة الحياة في ظل جائحة كورونا "COVID . 19" (عبدالناصر السيد عامر): المجلة التربوية، كلية التربية ـ جامعة سوهاج،

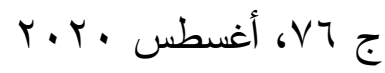
- إسهام الصمود النفسي في جودة الحياة في ظل كورونا (عبد الناصر السيد عامر): المجلة التربوية 
لتداعيات جائحة كورونا لعام • ب • r، مركز الدراسات

الاستراتيجية ـ مكتبة الإسكندرية، يوليو . . . . . ـ دليل منظمة الأغذية والزراعة عن الإنتاج الحيواني وصحة الحيوان - الإنفلونزا والأمراض الحيوانية الأخرى المشتركة بين الإنسان والحيوان، التشاور العلمي المشترك بين منظمة الأغذية والزراعة والمنظمة العالمية للصحة الحيوانية ومنظمة الصحة

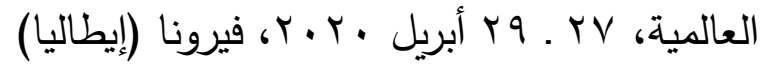
ـ دور وسائل الإعلام في تشكيل الوعي والمعرفة لدى أفراد المجتمع حول أزمة فيروس كوفيد_ 19 "المستجد" دراسة ميدانية على مستوى الوطن العربي (جاسم خليل ميرزا): جمعية الاجتماعيين في الشارقة،

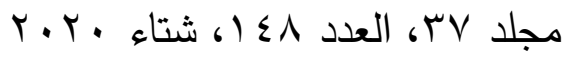
• علم الاجتماع (أنتوني غدنز): ، ترجمة وتقديم رمضان الصباغ، ط الرابعة ( ط الأولى ه . . ؟)، المؤسسة العربية للترجمة ـ مؤسسة ترجمان، بيروت ـ علم الأوبئة مقدمة قصيرة جدا (رودولفو ساراتشي): ترجمة أسامة فاروق حسن، ط الأولى، مؤسسة هنداوي 10 ـ فعالية استخدام تطبيقات الذكاء الاصطناعي الحديثة في مواجهة فيروس كورونا COVID. 19 تجربة كوريا الجنوبية نموذجا (أبوبكر الشريف خالد، خير الدين بوزرب): مجلة بحوث الإدارة والاقتصاد، جامعة عاشور بالجلفة . كلية العلوم الاقتصادية

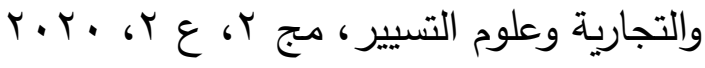

ـ الجوائح الوبائية والنظام الدولي، (مقال ـ بشير عبد

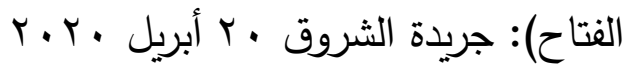
ـ الجوائح والسلطة والدين في المغرب زمن الوطاسيين - جوانب من تاريخ المغرب العميق (عبدالله استيتو): جامعة ابن زهر ـ كلية الآداب والعلوم الإنسانية، ع $r \cdot 196 r r$ ـ الجوائح وتداعياتها الاقتصادية المطولة (أوسكار

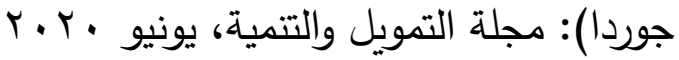
ـ الطلبة الجامعيون بين القيم السائدة والقيم المتحية: دراسة نظرية ميدانية (نجوى عميرش): رسالة

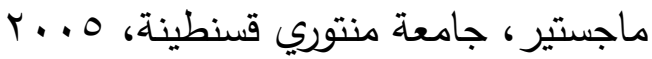
ـ العوامل المؤثرة على السلوك الاتصالي للجمهور المصري في أثناء ازمة فيروس كورونا ـ دراسة ميدانية (إيمان صادق صابر): مجلة بحوث العلاقات العامة

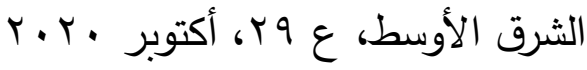
- إنفلونزا الخنازير، كلية الزراعة ( إعداد ـ أحمد عبدالرازق جبر ): جامعة المنصورة، مصر 9 . . - برنامج التواصل الاجتماعي ( إعداد ـ عيسى بن سليمان الفيفي): ، نسخة الكترونية بrع أ هـ ـ تاريخ الأوبئة وتأثيراتها على المجتمعات الإنسانية (أنسية حوار ـ لوران هنري فينيو): أخبار الخليج، ب مايو $r . r$. ـ تششي فيروس كورونا بين المؤامرة والتعاون الدولي (محمود عزت عبدالحافظ): ضمن: سوزان عابد (تحرير): تداعيات الجائحة . رؤى تحليلية ونقدية 
V.

تموشنت ـ معهد العلوم الاقتصادية، التسيير والعلوم

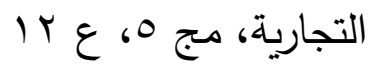

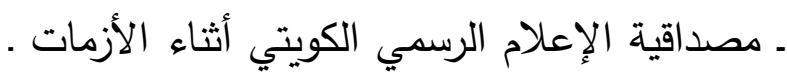

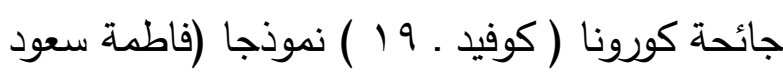
عبدالعزيز السالم): مجلة بحوث العلاقات العوفئات العامة

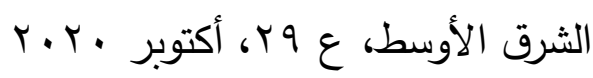

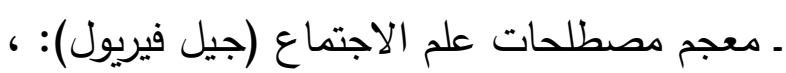
ترجمة وتقديم أسنام محمد الأسعد، ط الأولى، دار

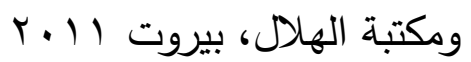

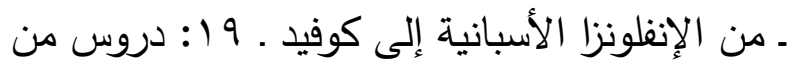

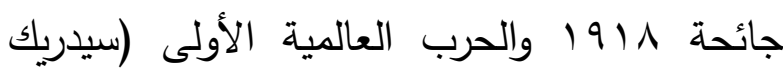
كوتر): ، مجلة الإنساني . مجلة تصدر عن المركز

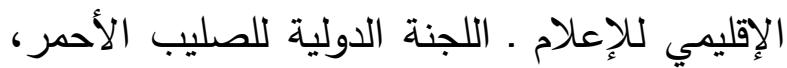
G.Y. مايو /https://blogs.icrc.org/alinsani/2020/05/12/19-1918 ـ نشرة المعهد الديمقراطي الوطني: خطة التعامل مع الأزمة ـ دليل عملي للسياسيين للتعامل مع جائحة

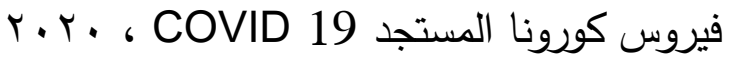

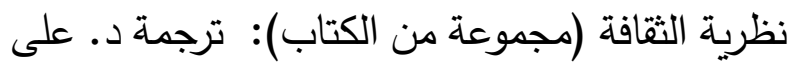
سيد الصاوي، عالم المعرفة، يوليو 1997
ـ فعالية استخدام تطبيقات الذكاء الاصطناعي الحديثة. في مواجهة فيروس كورونا COVID . 19 ـ كوريا الجنوبية نموذجا (أبوبكر الشريف خوالد، خيرالدين محمود بوزرب): مجلة بحوث الإدارة والاقتصاد، كلية

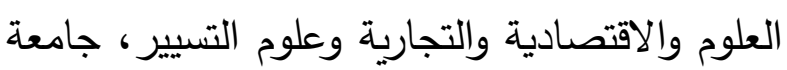

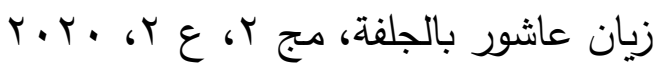
ـ كورونا في إفريقيا ـ فرص ونجاحات (افتتاحية ـ هيئة التحرير ): مجلة قراءات إفريقية، المنتدى الإسلامي، وردي،

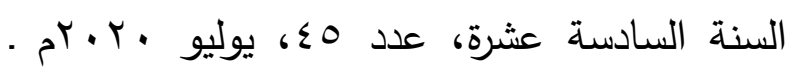
ه $1 \leq \leqslant 1$ ـ لسان العرب ، دار المعارف، القاهرة، بدون

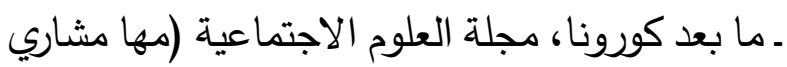

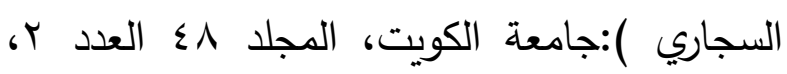
$r \cdot r \cdot$ ـ مساهمة الدفع الإلكتروني في تعزيز الثمول المالي والوقاية من جائحة كورونا في الجزائر: البطاقة الذهبية لبريد الجزائر أنموذجا (علاوي نواري ، حماني

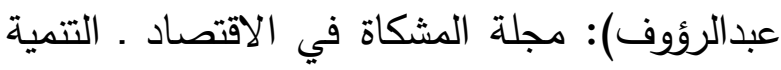
والقانون، المركز الجامعي بلحاج بوشعيب عين 


\title{
Communication during historical pandemics - a comparison between the Spanish flu pandemic and the 2019 corona pandemic - an interdisciplinary study.
}

\author{
D.Hassan Abdullah Alasmari \\ Assistant Professor \\ College Of Science \& Arts - Rabigh
}

\begin{abstract}
And to achieve the goal of the study, a descriptive approach was used to describe the general framework of the phenomenon related to major pandemics in general, and the influenza pandemics of 1920 and Covid 19 In particular, and a comparative approach was used, in order to clarify the practical differences between the two pandemics; Especially with regard to social communication. This study reached several conclusions, the most important of which is that pandemics are a human phenomenon that recurs in human life, and unfortunately the main cause of their occurrence is related to human behavior. Especially with regard to his personal habits related to food and public health, and in the face of the risks, economic losses and social impacts caused by these pandemics, the role of social media and satellite channels becomes more central and important in facing these effects, especially with the possibility of direct work and commerce from home.
\end{abstract}

Key Words: Social Media, Pandemics, Influenza, Covid-19. 


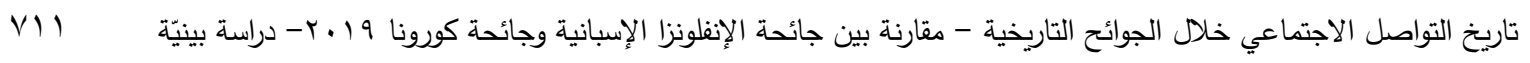

